\title{
Thermodynamic properties of seawater, ice and humid air: TEOS-10, before and beyond
}

\author{
Rainer Feistel ${ }^{1, *}$ \\ ${ }^{1}$ Leibniz Institute for Baltic Sea Research (IOW), Warnemünde, 18119, Germany \\ * Invited contribution by Rainer Feistel, recipient of the EGU Fridtjof Nansen Medal 2018.
}

Correspondence: Rainer Feistel (rainer.feistel@io-warnemuende.de)

Received: 22 February 2018 - Discussion started: 7 March 2018

Revised: 16 May 2018 - Accepted: 23 May 2018 - Published: 14 June 2018

\begin{abstract}
In the terrestrial climate system, water is a key player in the form of its different ambient phases of ice, liquid and vapour, admixed with sea salt in the ocean and with dry air in the atmosphere. For proper balances of climatic energy and entropy fluxes in models and observations, a highly accurate, consistent and comprehensive thermodynamic standard framework is requisite in geophysics and climate research. The new Thermodynamic Equation of Seawater 2010 (TEOS-10) constitutes such a standard for properties of water in its various manifestations in the hydrological cycle. TEOS-10 was recommended internationally in 2009 by the Intergovernmental Oceanographic Commission (IOC) to replace the previous 1980 seawater standard, EOS-80, and in 2011 by the International Union of Geodesy and Geophysics (IUGG) "as the official description for the properties of seawater, of ice and of humid air". This paper briefly reviews the development of TEOS-10, its novel axiomatic properties, the new oceanographic tools it offers and the important tasks that still await solutions by ongoing research. Among the latter are new definitions and measurement standards for seawater salinity and $\mathrm{pH}$ in order to establish their metrological traceability to the International System of Units (SI) for the first time after a century of widespread use. Of similar climatological relevance is the development and recommendation of a uniform standard definition of atmospheric relative humidity that is unambiguous and rigorously based on physical principles.
\end{abstract}

"The leading thermodynamic properties of a fluid are determined by the relations which exist between volume, pressure, temperature, energy, and entropy ...

But all the relations existing between these five quantities for any substance ... may be deduced from the single relation existing for that substance between volume, energy, and entropy.'

Josiah Willard Gibbs, 1873b

\section{Introduction}

In the context of recent global warming and the anthropogenic greenhouse effect of carbon dioxide $\left(\mathrm{CO}_{2}\right)$, the pivotal article of Svante Arrhenius (1896) found public attention well beyond the scientific communities of meteorologists and climatologists. Much less known, however, is the lecture by Heinrich Hertz given in 1885 in which he analysed the thermodynamics of the hydrological cycle in the climate system as a "gigantic steam engine" (Mulligan and Hertz, 1997, p. 41). In fact, rather than $\mathrm{CO}_{2}$, water in the troposphere in the form of humidity and clouds contributes the major part to the overall greenhouse effect (Abbot and Fowle Jr., 1908; Emden, 1913; Trenberth et al., 2007; Lacis et al., 2010; Schmidt et al., 2010; Feistel and Ebeling, 2011; Feistel, 2015, 2017; Lovell-Smith et al., 2016). The global water cycle, along with its observation and modelling, poses a fundamental challenge for climate research (Sherwood et al., 2010; Reid and Valdés, 2011; Tollefsen, 2012; Fasullo and Trenberth, 2012; Josey et al., 2013; Stevens and Bony, 2013; IPCC, 2013).

Together with freshwater lakes and rivers, polar ice caps, humid air and clouds, saline water in the oceans forms a highly dynamic, coupled system of water in different phases and mixtures. Densities, heat capacities and the latent heats of mutual phase transitions of water play a key role for the 
transformation and distribution processes of energy between the initial absorption of incoming solar radiation and the final export of thermal radiation. Comprehensive, consistent and quantitative knowledge of water properties in its various appearances is requisite for the analysis of measurements and the development of numerical models. Moreover, climate research is carried out at various places in the world and extends over time spans of several human generations. Mutual comparability of research results is indispensable, which rigorously requires that well-defined, highly accurate international standards must be applied, such as the International System of Units (SI).

TEOS-10, the Thermodynamic Equation of Seawater 2010, constitutes such an international standard for the thermodynamic properties of water in the climate system. In addition to seawater in particular, it also covers the properties of ice and humid air in a perfectly consistent, comprehensive way with unprecedentedly high accuracy. By the numerical coefficients of its empirical thermodynamic potentials, TEOS-10 represents in a mathematically most compact way the results of an enormous amount of very different experimental studies of water, ice, seawater and air properties. TEOS-10 was recommended internationally in 2009 by the Intergovernmental Oceanographic Commission (IOC) to replace the previous 1980 seawater standard, EOS80, and in 2011 by the International Union of Geodesy and Geophysics (IUGG) "as the official description for the properties of seawater, of ice and of humid air". Beginning in 2006, TEOS-10 was developed in close cooperation between the SCOR/IAPSO Working Group 127 on Thermodynamics and Equation of State of Seawater (WG127) and the International Association for the Properties of Water and Steam (IAPWS). TEOS-10 is officially defined by its manual (IOC et al., 2010) and is supported by open-source software libraries (available from the internet at the TEOS-10 home page, www.teos-10.org, last access: 7 June 2018), several open-access IAPWS documents (IAPWS AN6-16, 2016) and various supporting scientific articles, such as the definition of the new Reference-Composition Salinity Scale (Millero et al., 2008) and a new thermodynamic definition of relative humidity (Feistel and Lovell-Smith, 2017). A collection of background articles on TEOS-10 was published as a Special Issue of Ocean Science (Feistel et al., 2008b).

This paper is organised as follows. Thermodynamic potentials are not necessarily taught in courses of oceanography or other geosciences, so Sect. 2 provides a short introduction to this theoretical method developed about 150 years ago. The most convenient mathematical formalism of manipulating partial derivatives with different sets of variables, as necessary for the work with those potentials, is the Jacobi method explained in Appendix A. Section 3 describes the details of the development of the thermodynamic potentials for fluid water, ice, seawater and humid air, which constitute the core of TEOS-10, together with the scales used for temperature and salinity. Section 4 deals with the structure of TEOS-10, its axiomatic approach to the computation of thermodynamic properties and the digital, open-source libraries provided by TEOS-10. Members of the SCOR/IAPSO Working Group 127 , who participated in the annual meetings and successfully completed these demanding tasks within a few years of intense cooperative work, can be found in Appendix B. Section 5 describes three important pending problems that still await solutions beyond TEOS- 10 .

The relatively large number of references cited in this review includes numerous sources that are of relevance in the context of TEOS-10 and belong to a variety of different scientific disciplines. However, these references do not even include the extensive lists of numerous experimental works that provided the fundamental property data of water, seawater, ice and humid air ultimately being represented by TEOS-10 in an integrated, compact form.

\section{Thermodynamic potentials}

A thermodynamic potential is a mathematical function from which all thermodynamic properties of a given many-particle system at equilibrium can be derived using formal thermodynamic rules. The system under study may be a pure substance such as water or ice, a mixture such as seawater or humid air, or a multi-phase composite such as sea ice (ice with brine pockets) or a cloud (air with liquid droplets). J. Willard Gibbs discovered the existence of such functions already in 1873 (Gibbs, 1873a, b), but their practical use remained limited before powerful computers became commonplace in science. In contrast, thermodynamic potentials have always played a key role in theoretical physics (Landau and Lifschitz, 1966). The partition functions of statistical thermodynamics are mathematical expressions for the Boltzmann entropy, the Helmholtz potential and the Landau potential, respectively, obtained from the micro-canonical, canonical and grand canonical ensembles.

Depending on which external conditions are imposed on a given sample, an associated potential function needs to be chosen. For example, if we know the temperature $T$, the volume $V$ and the total mass $m$, the potential to be used is the Helmholtz energy, $F(m, T, V)$, or similarly, as a function of temperature and density, $\rho$, the specific Helmholtz energy, $f$ $(T, \rho)=F / m$. A typical case of such conditions is an experimental set-up of a liquid or gas in a given rigid container in order to measure the pressure or the isochoric heat capacity at different temperatures or densities. In geophysics, such as in the atmosphere or in the ocean, typically the pressure $p$ rather than the volume of a fluid parcel is available. Then, the Gibbs energy $G(m, T, p)$, or similarly, the specific Gibbs energy, $g(T, p)=G / m$, is the appropriate potential from which properties of interest, such as the density, entropy or enthalpy of the parcel, can be computed. For brevity, the terms Gibbs function and Helmholtz function, respectively, are used in this paper for the specific Gibbs and Helmholtz 
energies expressed in terms of their particular natural independent variables. The two potentials may be converted into each other, if either $f(T, \rho)$ is known, by

$g(T, p)=f+\rho \frac{\partial f}{\partial \rho}, \quad p=\rho^{2} \frac{\partial f}{\partial \rho}$

or, if $g(T, p)$ is given, by

$f(T, \rho)=g-p \frac{\partial g}{\partial p}, \quad \rho^{-1}=\frac{\partial g}{\partial p}$.

Transformation equations of this kind between different sets of independent variables are commonly known as Legendre transforms (Margenau and Murphy, 1943; Landau and Lifschitz, 1966; Alberty, 2001). Another potential function of significant interest in TEOS-10 is the specific enthalpy $h(\eta$, $p)$ as a function of the specific entropy, $\eta$, and the pressure. It is derived from a TEOS-10 Gibbs function $g(T, p)$ by the Legendre transform

$h(\eta, p)=g-T \frac{\partial g}{\partial T}, \eta=-\frac{\partial g}{\partial T}$,

and from a TEOS-10 Helmholtz function $f(T, \rho)$ by

$$
\begin{gathered}
h(\eta, p)=f-T \frac{\partial f}{\partial T}+\rho \frac{\partial f}{\partial \rho}, \\
\eta=-\frac{\partial f}{\partial T}, \quad p=\rho^{2} \frac{\partial f}{\partial \rho} .
\end{gathered}
$$

The partial derivatives are understood here as being taken at constant values of the respective other so-called "natural" independent variables associated with a given potential.

Potential functions, such as $F, f, G, g$ or $h$ above, may also be expressed in terms of alternative independent variables, but then they may lose their capabilities as potential functions from which all other quantities may be derived. For example, entropy can only incompletely be computed from the function $h(T, p)$. The "original" thermodynamic potential studied by Gibbs (see his initial quotation) was internal energy as a function of volume and entropy; this function is rarely used in geophysics or engineering, mainly because its input parameter entropy cannot be measured experimentally (Tillner-Roth, 1998). Among the most relevant measurable properties derived from the potential functions above are density, $\rho$,

$\frac{1}{\rho}=\frac{V}{m}=\left(\frac{\partial g}{\partial p}\right)_{T}=\left(\frac{\partial h}{\partial p}\right)_{\eta}$,

isobaric specific heat capacity, $c_{p}$,

$c_{p}=\left(\frac{\partial h}{\partial T}\right)_{p}=T\left(\frac{\partial \eta}{\partial T}\right)_{p}=-T\left(\frac{\partial^{2} g}{\partial T^{2}}\right)_{p}$,

$$
\begin{aligned}
& \frac{1}{c^{2}}=\left(\frac{\partial \rho}{\partial p}\right)_{\eta}=-\varrho^{2}\left(\frac{\partial^{2} h}{\partial p^{2}}\right)_{\eta} \\
&=\varrho^{2} \frac{\left(\frac{\partial^{2} g}{\partial p \partial T}\right)^{2}-\left(\frac{\partial^{2} g}{\partial T^{2}}\right)_{p}\left(\frac{\partial^{2} g}{\partial p^{2}}\right)_{T}}{\left(\frac{\partial^{2} g}{\partial T^{2}}\right)_{p}},
\end{aligned}
$$

and the adiabatic lapse rate, $\Gamma$,

$\Gamma=\left(\frac{\partial T}{\partial p}\right)_{\eta}=\frac{\partial^{2} h}{\partial \eta \partial p}=\frac{\frac{\partial^{2} g}{\partial T \partial p}}{\left(\frac{\partial^{2} g}{\partial T^{2}}\right)_{p}}$.

Here, for uniqueness of the mathematical expressions, the subscripts at the brackets indicate the variables that are kept constant when the partial derivative is carried out. Extended lists of such thermodynamic relations for the various quantities implemented in TEOS-10 are available from the manual (IOC et al., 2010) and from the digital Supplements of Feistel et al. (2010a) and Wright et al. (2010a). The conversion of formulas from one set of independent variables to another is done using the chain rule of differential calculus. In a convenient multi-variable version, this rule is known as the Jacobi method. Appendix A demonstrates this method tutorially and how it is applied to derive formulas like Eqs. (5)-(8) in a straightforward manner, such as Eq. (A18) for the sound speed.

In order to quantitatively determine a thermodynamic potential for a given substance of interest, a suitable but largely arbitrary mathematical expression for the potential function is designed by trial and error. The function depends on a set of $N$ adjustable parameters, say $\boldsymbol{a}=\left(a_{1}, \ldots a_{N}\right)$, which are estimated by simultaneous numerical regression with respect to all reliable experimental data available for the properties given by Eqs. (5)-(8) and others. For each substance involved, two of those parameters remain unknown, representing the absolute energy and absolute entropy of that substance, unavailable from thermodynamic measurements. These parameters are usually specified by conventionally assuming certain values to selected quantities at a chosen reference state. In TEOS-10, the internal energy and entropy of liquid water are assumed to take zero values at the common solid-liquid-gas triple point. Similar assumptions were also employed for dry air and dissolved sea salt; see Sect. 3. For consistency, it is important to implement for any given substance the same conventional values in any mixture or phase where it is present, such as for the water substance $\mathrm{H}_{2} \mathrm{O}$ in ice, in seawater and in humid air (Feistel et al., 2008a).

sound speed, $c$, 


\section{Fundamental thermodynamic potentials of TEOS-10}

\subsection{Temperature scales}

For the measurement of temperatures, temperaturedependent properties of certain materials are frequently used, such as the volume expansion of liquid mercury or the electrical resistance of platinum. Sensors of this kind need to be calibrated; that is, a quantitative relation between that property and selected numerical temperature values must be specified. For the currently valid International Temperature Scale of 1990 (ITS-90), "the unit of the fundamental physical quantity known as thermodynamic temperature, symbol $T$, is the kelvin, symbol $\mathrm{K}$, defined as the fraction $1 / 273.16$ of the thermodynamic temperature of the triple point of water" (Preston-Thomas, 1990). In practice, many published geophysical property equations are expressed in terms of earlier, obsolete scales, such as the International Practical Temperature Scale of 1968, IPTS-68. Among those obsolete equations are, in particular, the International Equation of State of Seawater, EOS-80, and the Practical Salinity Scale of Seawater, PSS-78 (Unesco, 1981a, b, 1983).

TEOS-10 is expressed in terms of ITS-90. Experimental data were converted from their original values according to the transformation rules published by Rusby (1991), Goldberg and Weir (1992), Rusby et al. (1994), and Weir and Goldberg (1996). In the vicinity of the triple point of water, the deviations between different temperature scales are generally small, in particular for oceanographic applications (Saunders, 1990; Feistel and Hagen, 1995; Feistel, 2008a). ITS-90 is expected to remain in practical use for the foreseeable future.

On 20 May 2019, World Metrology Day, a so-called "new SI" is expected to become formally introduced at the International Bureau of Weights and Measures (BIPM) in Sèvres near Paris. Along with it, a new thermodynamic temperature scale will be established in 2018 (Fellmuth et al., 2016; PTB, 2017; CCT, 2017; CGPM, 2018). This new temperature $T$ and the ITS- 90 temperature $T_{90}$ will be considered as two different physical quantities expressed in the same unit, namely the new kelvin (rather than being the same physical quantity expressed in two different units, $\mathrm{K}$ and a fictitious " $\mathrm{K}_{90}$ "). The definition of the kelvin contained in the 1990 definition will be superseded by the new kelvin definition in terms of the Boltzmann constant and the joule (CGPM, 2018). In ITS-90, the triple-point temperature of water will remain at exactly $T_{90}=273.16 \mathrm{~K}$. This value will also be valid for the thermodynamic temperature but only within an uncertainty yet to be specified, likely about $160 \mu \mathrm{K}$. By definition, the Boltzmann constant, $k=1.380649 \times 10^{-23} \mathrm{~J} \mathrm{~K}^{-1}$, the Avogadro constant, $N_{\mathrm{A}}=6.02214076 \times 10^{23} \mathrm{~mol}^{-1}$, and the molar gas constant, $R=k \cdot N_{\mathrm{A}}$, will take eternally fixed, exact values in the new SI (Fischer, 2016; PTB, 2017). This is a very practical future aspect as the various IAPWS documents supporting TEOS-10 implement several slightly dif- ferent values of the gas constant according to varying official values it took at the time the particular document was developed (IAPWS G5-01, 2016).

\subsection{Helmholtz function of fluid water}

The joint Helmholtz function, $f^{\mathrm{F}}(T, \rho)$, of fluid water published by Wagner and Pruß (2002), also known as the IAPWS-95 equation, is identical to the Helmholtz functions of liquid water, $f^{\mathrm{F}} \equiv f^{\mathrm{W}}$, and water vapour, $f^{\mathrm{F}} \equiv f^{\mathrm{V}}$, and represents a key constituent of TEOS-10. In compact form, the latest version of this equation is available from IAPWS R6-95 (2016). Since its first release in 1995, the latter document has undergone several minor revisions without affecting the calculated values of any measurable properties. The equation is also available from several other references, such as IOC et al. (2010) and Feistel et al. (2010b). The formulation is valid in the entire stable fluid region of $\mathrm{H}_{2} \mathrm{O}$ from the melting curve to $1273 \mathrm{~K}$ at pressures up to $1000 \mathrm{MPa}$; the lowest temperature on the melting curve is $251.165 \mathrm{~K}$ at $208.566 \mathrm{MPa}$ (Wagner et al., 2011; IAPWS R14-08, 2011); see Fig. 1. As an additional part of TEOS-10, a low-temperature extension of the IAPWS-95 equation for water vapour down to $50 \mathrm{~K}$ is given by Feistel et al. (2010b) and IAPWS G9-12 (2012). IAPWS-95 is valid for air-free water with an isotopic composition of Vienna Standard Mean Ocean Water, VSMOW (IAPWS G5-01, 2016).

Helmholtz functions are preferred description tools for fluids because they may cover the wide density range from the gas to the liquid phase by a single, unique formula. In contrast, Gibbs functions take multiple values in the $T-p$ vicinity of the saturation curve where liquid and gas coexist so that in practice two separate Gibbs functions, $g^{\mathrm{W}}$ and $g^{\mathrm{V}}$, respectively, are specified for liquid and vapour. Consistent with TEOS-10, there is an equation for the Gibbs function for liquid water under oceanographic conditions (Feistel, 2003; IAPWS SR7-09, 2009), an equation for the Gibbs function for liquid water at atmospheric pressure (Pátek et al., 2009; IAPWS SR6-08, 2011) and a virial expansion of the Gibbs function for water vapour (Feistel et al., 2015). Recently, a Gibbs function for supercooled, metastable liquid water has also been developed (IAPWS G12-15, 2015) which is not included in TEOS-10.

For a pure substance, the chemical potential equals its Gibbs function. Consequently, along the saturation curve, $p^{\text {sat }}(T)$, in the $(T, p)$ diagram from the common triple point to the critical point of water (see Fig. 1), the Gibbs function of liquid water equals the Gibbs function of water vapour, $g^{\mathrm{W}}\left(T, p^{\text {sat }}\right)=g^{\mathrm{V}}\left(T, p^{\text {sat }}\right)$. From this equilibrium condition, the saturation pressure as a function of the temperature, $p^{\text {sat }}(T)$, can be calculated iteratively. A simple analytical approximation formula of this solution is available (IAPWS SR1-86, 1992). While the values of the Gibbs functions of the two phases coincide along the saturation curve, $g^{\mathrm{W} \text {,sat }}=g^{\mathrm{V} \text {,sat }}$, their partial temperature and pressure deriva- 


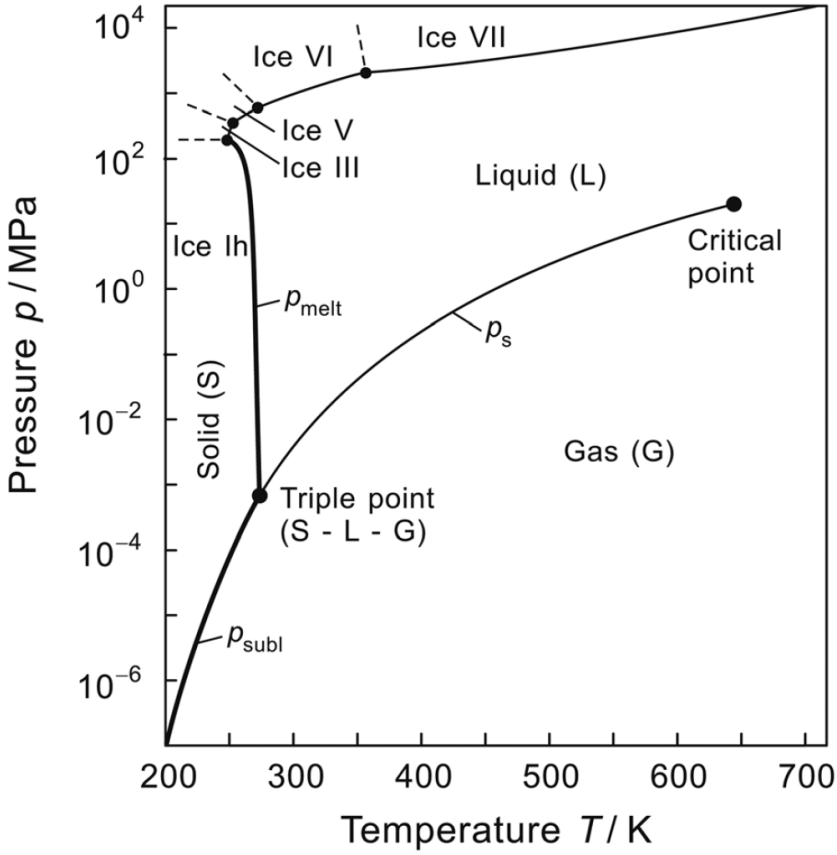

Figure 1. Temperature-pressure diagram of water (from IAPWS R14-08, 2011, permitted). The curves indicate phase transitions between stable gaseous, liquid and solid states; $p_{\text {melt }}$ indicates the melting line of ambient hexagonal ice $\mathrm{Ih}, p_{\text {subl }}$ its sublimation line and $p_{\mathrm{s}}$ the saturation line, or boiling line, between liquid and gas. Several additional ice phases are not indicated. Within this diagram, geophysical conditions for ice, liquid water and water vapour cover only small regions (not shown) in the vicinity of the triple point.

tives, namely the specific entropies and volumes, respectively, of liquid and vapour are different there, except at the critical point itself.

In their common ranges of validity, IAPWS-95 is consistent with the most accurate metrological equation of state of liquid water, the so-called CIPM-2001 equation (Tanaka et al., 2001; Harvey et al., 2009; IAPWS AN4-09, 2009). This means that under ambient conditions, density is known within an uncertainty of $1 \mathrm{ppm}$. This accuracy permits the use of IAPWS-95 for the calibration of high-precision density meters (Wolf, 2008). By means of such instruments, seawater salinity may be determined from measured densities, and sea-salt composition anomalies may be detected (Millero et al., 2008; Feistel et al., 2010c; Wright et al., 2011; Woosley et al., 2014; Pawlowicz et al., 2016; Schmidt et al., 2016, 2018; Budéus, 2018); see also Sect. 3.4.

In TEOS-10, the IAPWS-95 equation replaced the earlier equations of state of liquid water from Bigg (1967) and Kell (1975), on which the former seawater standard EOS-80 was based (Unesco, 1981b). This change in the pure-water equation made it possible to resolve systematic problems previously encountered with the sound speed of seawater at high pressures (Dushaw et al., 1993; Millero and Li, 1994; Feistel, 2003); see also Sect. 3.5.

\subsection{Gibbs function of ice Ih}

Hexagonal ice I, or ice Ih, is the only stable solid phase of water in the terrestrial atmosphere, hydrosphere and cryosphere (in contrast to metastable cubic ice I, or ice Ic, which appears temporarily in cloud formation processes, or ices II, III, etc., found in the lab at very high pressures or very low temperatures). Several textbooks on ice were published in the past, such as those by Dorsey (1968), Hobbs (1974) and Petrenko and Whitworth (1999), offering separate empirical equations for selected properties. The first Gibbs functions for ice Ih were developed by Feistel and Hagen (1995, 1998) and Tillner-Roth (1998), valid in the vicinity of the melting curve. Including numerous additional data, the two approaches were combined by Feistel and Wagner (2004, 2005, 2006, 2007; IAPWS R10-06, 2009) for an IAPWS equation for ice Ih that covers a wide range of temperatures and pressures and is significantly more accurate than several single-property equations published before. Theoretically, a Helmholtz function for ice Ih can smoothly be combined with that for fluid water into a single three-phase Helmholtz function for water, valid everywhere near the triple point, but such an attempt has not yet been made.

The measurement of ice properties is experimentally challenging, in particular for sluggish ageing effects; if ice is brought under different temperature or pressure conditions, the establishment of the related new equilibrium crystal structure may take hours or even days until completion. Consequently, measurement series conducted too quickly may suffer from the risk of systematic hysteresis effects. Published data on ice compressibility vary up to a factor of 3.6 between different authors. In TEOS-10, the related uncertainty of mechanical measurements could be reduced by a factor of 100 to about $1 \%$ (Feistel and Wagner, 2004, 2005) using crystallographic spectroscopy data (Gammon et al., 1980, 1983; Gagnon et al., 1988); see Fig. 2.

The chemical potential of a pure substance equals its Gibbs function. Consequently, along the freezing curve in the $(T, p)$ diagram in Fig. 1, the Gibbs function of ice $\mathrm{Ih}$ equals the Gibbs function of liquid water, and along the sublimation curve, the Gibbs function of ice Ih equals the Gibbs function of water vapour. From these equilibrium conditions, the freezing pressure and the sublimation pressure as functions of the temperature can be calculated iteratively. Convenient analytical approximation formulas are available for both curves (Wagner et al., 2011; IAPWS R14-08, 2011).

It is well known that the latent heats of evaporating or freezing water possess exceptionally large values and that this fact plays an important role in the climate system. The latent heat of sublimation is less familiar, even though it amounts to the sum of the latent heats of melting and evaporation. Air is dry under the polar high-pressure cells of the troposphere, and the sublimation rates of glaciers, icebergs and polar ice caps are significant there. Antarctic dry valleys are famous for their extreme conditions. Sublimation fluxes 


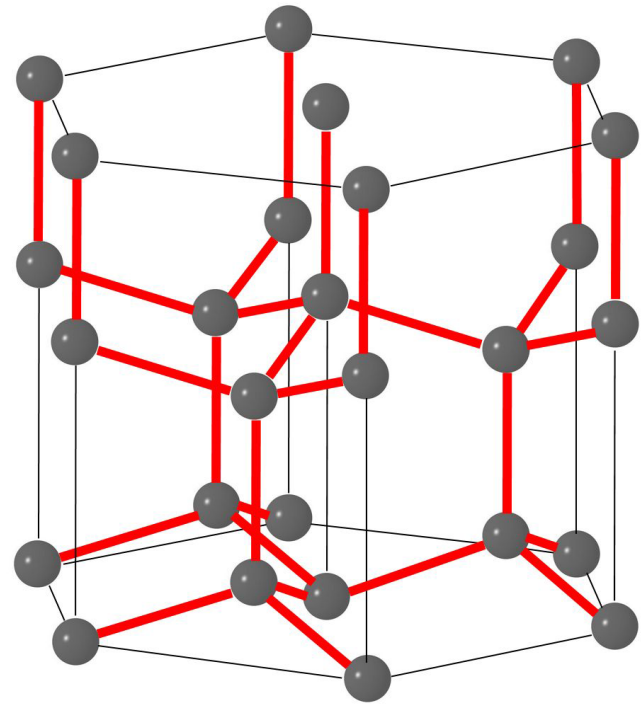

Figure 2. The hexagonal elementary crystal of ice Ih (Penny, 1948; Schulson, 1999) consists of 27 oxygen (O) atoms (spheres) and 28 hydrogen $(\mathrm{H})$ bonds between them (bars). Of the four $\mathrm{H}$ atoms adjacent to each $\mathrm{O}$ atom, two are placed closer than the other pair, thus retaining the structure of individual $\mathrm{H}_{2} \mathrm{O}$ molecules within the crystal lattice. Despite the crystal's anisotropy, thermodynamic ice properties are isotropic to within measurement uncertainty.

are approximately driven by relative humidity, which in turn is governed by the sublimation pressure of ice. In TEOS10 , the sublimation pressure can be calculated directly from the thermodynamic potentials of ice and vapour; it turned out that the uncertainty of those computed TEOS-10 values for the sublimation pressure is typically about a factor of 10 smaller than the uncertainty of the most accurate direct measurements, such as those of Fernicola et al. (2012) and Bielska et al. (2013). The limitation of accuracy of the computed values results mainly from the uncertainty of the heat capacity data of ice and water vapour that entered the thermodynamic potentials (Wagner et al., 2011). Moreover, the estimated upper and lower bounds of the heat capacity values of water vapour result directly in corresponding lower and upper bounds for the computed sublimation temperature at given pressure (Feistel and Wagner, 2007). The TEOS-10 equation extends to much lower temperatures and pressures than other standard formulas, such as that of Murphy and Koop (2005), and covers conditions inaccessible for presentday direct measurements. For these reasons, TEOS-10 and its sublimation-pressure equation are preferable for geophysical applications such as models of ice clouds down to temperatures of $80 \mathrm{~K}$ (Lübken et al., 2009).

Another distinctive feature of the TEOS-10 ice equation is its exceptional accuracy in ITS-90 freezing temperatures of air-free water, such as $273.152519 \mathrm{~K}$ at atmospheric pressure, $1013.25 \mathrm{hPa}$, within an uncertainty of just $2 \mu \mathrm{K}$ (Feistel and Wagner, 2005, 2006; Feistel, 2012; Feistel et al., 2016).
For air-saturated water, this freezing point is lowered to the common ice point of $273.150019 \mathrm{~K}$ with an estimated uncertainty of $5 \mu \mathrm{K}$ (Harvey et al., 2013).

\subsection{Salinity scales}

Dominated by common salt $(\mathrm{NaCl})$ and hair salt $\left(\mathrm{MgSO}_{4}\right)$, seawater is a complicated electrolyte solution containing numerous chemical elements. Salinity is the general term used to quantify the amount of dissolved sea salt; however, seawater salinity was defined and measured in different ways in the past and expressed in different units (Forch et al., 1902; Sverdrup et al., 1942; Lyman, 1969; Wallace, 1974; Lewis and Perkin, 1978; Unesco, 1981c). The reason for this confusing variety lies in the theoretical and practical difficulties of precisely specifying and measuring the kind and amount of solute in a given seawater sample (Millero et al., 2008; Wright et al., 2011; Pawlowicz et al., 2016). While the ratios of the main sea-salt components are strikingly similar in all oceans, a historical observation known as the Marcet rule (Millero et al., 2008), regional deviations from this rule may no longer be ignored as mostly done before TEOS- 10 . However, the stoichiometry of real sea salt is currently still not known well enough so that artificial seawater could be produced from the chemical constituents in the laboratory to sufficiently match all the properties of natural IAPSO Standard Seawater (SSW) collected from the North Atlantic.

TEOS-10 is formulated in terms of absolute salinity, $S_{\mathrm{A}}$, defined as the mass fraction of sea salt dissolved in water, usually expressed in grams of salt per kilogram of seawater (IOC et al., 2010). For SSW, the best estimate available for its absolute salinity is the reference-composition salinity, $S_{R}$, for short simply reference salinity, calculated from the atomic weights of the chemical constituents of sea salt (Millero et al., 2008). Present-day oceanographic measurement devices, however, report values of practical salinity, $S_{\mathrm{P}}$, which are computed from the electrical conductivity as defined by the Practical Salinity Scale of 1978, PSS-78 (Unesco, 1981a, 1983). Practical salinity is a unitless quantity, but because there are various other obsolete or non-standard, unitless salinity measures, some oceanographers prefer to attach "psu" (for "practical salinity unit") to reported figures of $S_{\mathrm{P}}$. This unofficial use of "psu" does not cause any harm but has been subject to forthright debates (Unesco, 1985, 1986; Millero, 1993). As an aside, a similar discussion is currently going on regarding the use of "\%rh" to denote unitless values of relative humidity $(\mathrm{RH})$ expressed in percent (Lovell-Smith et al., 2016) for an easier distinction between RH and, say, specific humidities or relative uncertainties of RH.

For SSW (and any other seawater as well), reference salinity is obtained from practical salinity by the formula

$S_{\mathrm{R}}=35.16504 \mathrm{~g} \mathrm{~kg}^{-1} S_{\mathrm{P}} / 35 \approx S_{\mathrm{P}} \cdot 1.004715 \mathrm{~g} \mathrm{~kg}^{-1}$.

For historical data, this equation can only be applied to salinity measurements carried out after 1978. Older legacy data 
are preferably converted from readings of chlorinity, $\mathrm{Cl}$, by

$S_{\mathrm{R}}=35.16504 \cdot 1.80655 \mathrm{Cl} / 35 \approx 1.815069 \mathrm{Cl}$.

Chlorinity is defined as the mass ratio of grams of pure silver necessary to precipitate the halogens (that is, chlorine, bromine, iodine) from $328.5234 \mathrm{~g}$ of seawater (Jacobsen and Knudsen, 1940; Sverdrup et al., 1942; Millero et al., 2008). By this definition, the chlorinity value is slightly greater than the mass fraction of chlorine in seawater, $w_{\mathrm{Cl}}=$ $0.9989041 \mathrm{Cl}$ (Millero et al., 2008). From the 19th century on, chlorinity values were rather consistently defined and determined by titration as the most accurate available salinity measure (Forch et al., 1902; Carritt, 1963; Lyman, 1969; Lewis, 1980; Pawlowicz et al., 2016; Burchard et al., 2018). In contrast, the unsatisfactory situation with the definition of salinity before PSS-78 was that "nobody has measured salinity for 60 years. At present chlorinity, conductivity and refractive index measurements are all being converted to "salinity" by inadequate tables of often doubtful origin. All make assumptions regarding constancy of relative proportions of the various ions, which are doubtful and may be quite unjustified, to the precision of our modern measurements" (Unesco, 1976, p. 2 therein).

Absolute salinity as defined in the context of TEOS-10 is the first officially revised measure of the mass fraction of salt dissolved in seawater (McDougall et al., 2008; Pawlowicz et al., 2016) after that of Knudsen and Sørensen more than a century ago (Forch et al., 1902). The associated reference composition is the first officially specified chemical standard composition for SSW (Millero et al., 2008). For seawater of this standard composition, the reference salinities from Eqs. (9) and (10) should result in numerical values that agree with each other within measurement uncertainty. Then, absolute salinity $S_{\mathrm{A}}$ is estimated from

$S_{\mathrm{A}}=S_{\mathrm{R}}$

to be used as a salinity input variable for TEOS-10 equations. However, salinities determined alternatively from both conductivity and chlorinity measurements somewhere in the world ocean may produce mutually inconsistent results. This happens especially if the chemical composition of seawater deviates from that of SSW, such as in the Baltic Sea (Wirth, 1940; Kwiecinski, 1965; Rohde, 1966; Millero and Kremling, 1976; Feistel et al., 2010c) or regionally in the global ocean (Millero et al., 1976, 2008, 2009, 2011; Tsunogai et al., 1979; Millero, 2000a; Pawlowicz, 2010; Wright et al., 2011; Uchida et al., 2011; McDougall et al., 2012; Woosley et al., 2014). In cases when Eqs. (9) and (10) do not match, the absolute salinity is estimated by

$S_{\mathrm{A}}=S_{\mathrm{R}}+\delta S_{\mathrm{A}}$

instead of Eq. (11) from density measurements or other suitable information, such as for the estimated actual composi- tion. The required correction,

$\delta S_{\mathrm{A}}=\frac{1}{\beta}\left\{\frac{\rho_{\text {meas }}}{\rho^{\mathrm{SW}}\left(S_{\mathrm{R}}\right)}-1\right\}$,

may be estimated using the measured density, $\rho_{\text {meas }}$, and the computed TEOS-10 seawater density, $\rho^{\mathrm{SW}}$, evaluated at the reference salinity and the same $T$ and $p$ given by Eq. (9); see Fig. 3. Here, $\beta$ is the haline contraction coefficient of seawater, which has a typical value of about 0.73 at $35 \mathrm{~g} \mathrm{~kg}^{-1}, 1000 \mathrm{hPa}$ and $300 \mathrm{~K}$. As a revival of previous, so-called specific-gravity methods (Forch et al., 1902; Krümmel, 1907), this density-based approach relies on the high accuracy of modern vibrating-tube density meters (Kremling, 1971; Wolf, 2008; Schmidt et al., 2016, 2018).

Before TEOS-10, the international standards attempted to avoid inconsistent results caused by using different methods of salinity determination. With the introduction of PSS78 , the further use of chlorinity titration was discouraged for this reason (Lewis and Perkin, 1978). TEOS-10 is the first international seawater standard in which chemical composition anomalies are explicitly accounted for. The simple use of Eq. (12) for calculating property anomalies from the TEOS-10 Gibbs function, rather than considering in detail the stoichiometry of the composition anomaly, is based on the heuristic, empirical "Millero rule", which argues "that the physical chemical properties of most lakes can be determined from equations for seawater at the same total salinity" (Millero, 2000b, p. 3 therein); see also Millero (1975) and Chen and Millero (1986). More specifically, Feistel et al. (2010d, pp. 958, 960 therein) explain that "this rule expresses the empirical finding that many aqueous solutions have very similar properties to that of standard seawater if only the temperature, the pressure and the mass fraction of dissolved solute are the same, independent of the details of the sample's chemical composition. Under the approximation of Millero's rule it is claimed in particular that

- absolute salinity of anomalous seawater can be computed from its density using the TEOS-10 equation of state and results in the same value at any temperature or pressure at which the density was measured, as well as that

- the properties of anomalous seawater can be computed from the TEOS-10 Gibbs function if absolute salinity is used as the composition variable, and finally, the first two rules combined, that

- the properties of anomalous seawater can be estimated by the TEOS-10 functions in terms of SSW properties evaluated at the same density, temperature and pressure".

TEOS-10 permits the description of global ocean properties with sufficient accuracy by implementing a single salinity variable, namely density salinity (IOC et al., 2010, Appendix A.20 therein; McDougall and Barker, 2011; Wright 


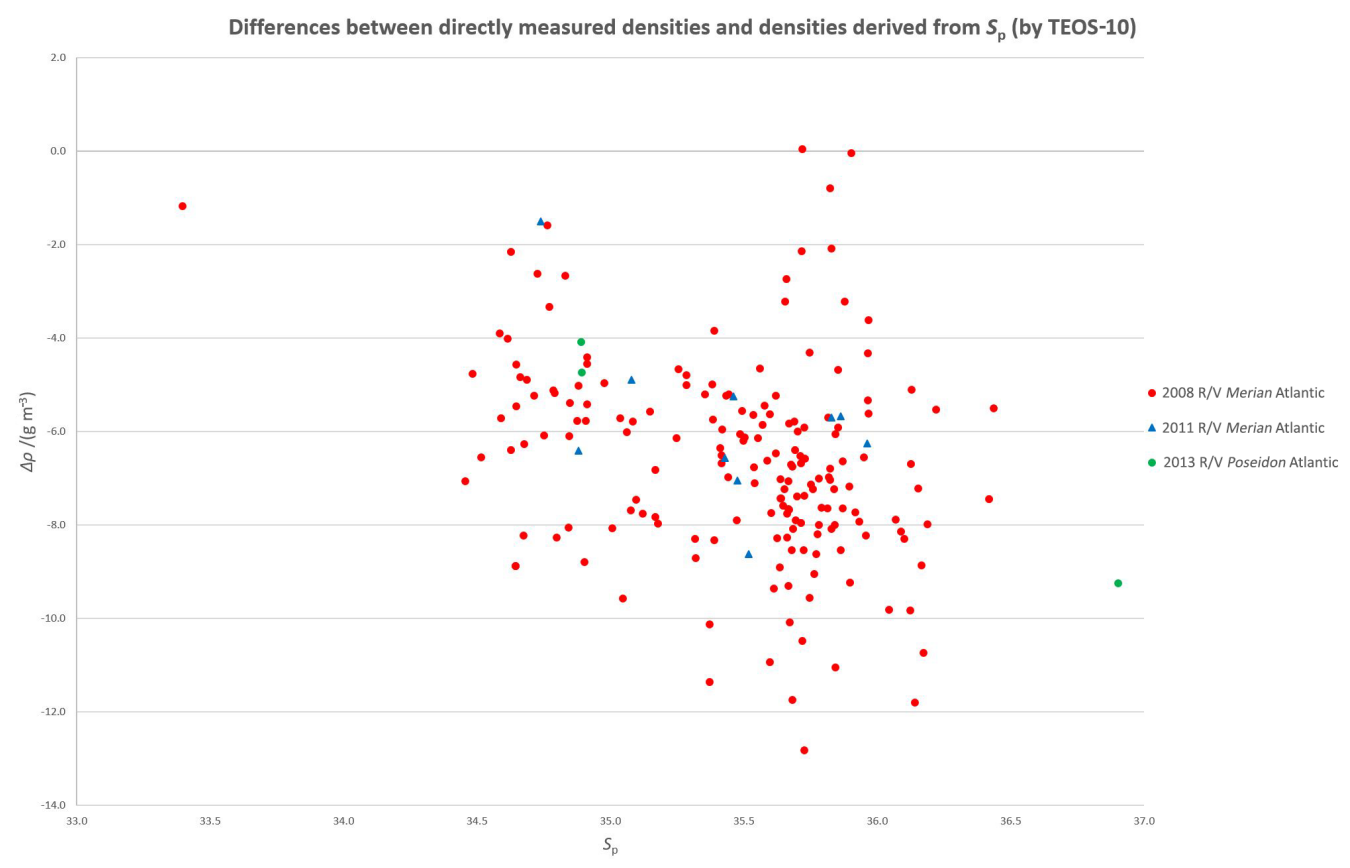

Figure 3. Example for differences between directly measured densities and values calculated from TEOS-10 with measured practical salinities, $S_{\mathrm{P}}$. Samples taken in 2008, 2011 and 2013 from eastern Atlantic surface waters between $33^{\circ} \mathrm{N}$ and $18^{\circ} \mathrm{S}$ show systematic negative density anomalies up to $13 \mathrm{ppm}$ (diagram courtesy Stefan Weinreben, IOW, personal communication, 2018).

et al., 2011), as an estimate of absolute salinity (Eq. 13). The density salinity of a sample is the salinity value of TEOS10 that matches the sample's given density, regardless of the composition. Evidently, by its definition, seawater density calculated from density salinity is exact. For other properties such as heat capacities or sound speeds, the effect of the composition anomaly is typically within the measurement uncertainty of that property, as the example of the Baltic Sea with its exceptionally large anomalies may demonstrate (Feistel et al., 2010d). In TEOS-10, density salinity is recommended as the current best estimate for the absolute salinity of arbitrary seawater, while reference-composition salinity is the current best estimate available for the absolute salinity of IAPSO Standard Seawater.

Not implemented in TEOS-10, by contrast, is an alternative approach of considering seawater composition anomalies by means of Pitzer equations and related numerical models, such as FREZCHEM (Marion and Grant, 1994; Feistel and Marion, 2007; Pawlowicz, 2008, 2010; Feistel et al., 2010d; Pawlowicz and Feistel, 2012). This method accounts for stoichiometric details, assuming a completely known solute composition, in contrast to Millero's rule, in which only the total mass of the solute is relevant, regardless of the particular composition. Pitzer equations for thermodynamic properties are power series in terms of the solute molalities, with empirical coefficients determined from various lab experiments. Composing a Gibbs function of Pitzer equations for standard and anomalous compositions (Feistel and Mar- ion, 2007; Feistel et al., 2010d) demonstrated that the currently known Pitzer coefficients permit accurate predictions for some properties (such as freezing points) but possess poor accuracies for others (such as sound speeds). For example, a significant sound speed anomaly of Baltic seawater predicted by the Pitzer model (Feistel et al., 2010d) could not be confirmed experimentally (von Rohden et al., 2016). For the Baltic Sea, such a Gibbs function with two independent salinity variables was explicitly compared with estimates based on absolute salinity as the single salinity variable of TEOS10 (Feistel et al., 2010d), and the latter, significantly less complicated approach proved sufficiently accurate. This finding is consistent with the detailed discussion of using more than one salinity variable in ocean models (IOC et al., 2010, Appendix A.20 therein; McDougall and Barker, 2011), concluding that density salinity is the key salinity variable. In addition to conservative equations governing the transport and mixing of absolute salinity in ocean models, further salinity variables may possibly be needed in order to implement the production and decay of specific salt components, such as nutrients, dissolved gases or radioactive substances, caused by biological, chemical or other processes within the water column.

While the validity of practical salinity is constrained to values of $S_{\mathrm{P}}$ between 2 and 42 (Unesco, 1981c), the new reference salinity can also be determined for higher concentrations because it is by its definition a physical mass fraction rather than a merely formal measure associated with the 
conductivity. Concentrated brines may be diluted with pure water until the salinity falls in the validity range of PSS-78. Then, $S_{\mathrm{P}}$ is measured, converted to $S_{\mathrm{R}}$ and, using the amount of added water and mass-conserving mixing rules, the reference salinity of the original sample is calculated (Millero at al., 2008).

\subsection{Gibbs function of seawater}

The thermodynamic properties of a Gibbs function for seawater were first discussed theoretically by Fofonoff (1962). However, in the context of the development of EOS-80, no attempt had been reported of actually constructing such a function numerically. The first practically implemented Gibbs function (Feistel, 1991, 1993; Feistel and Hagen, 1994) was consistent with EOS-80 and, beyond that, consistently provided additional properties such as entropy, enthalpy and the chemical potentials of water and sea salt that had partly been made available elsewhere before (Millero and Leung, 1976; Unesco, 1981b; Millero, 1983). The new approach to seawater thermodynamics was made public at the 1990 German-German Climate Conference in Gosen near Berlin, at the 1991 IUGG General Assembly in Vienna and at the 1993 AGU Chapman Conference on Fractals, Chaos, and Predictability in Oceanography and Meteorology in Galway, Ireland, as well as by personal communication with oceanographic experts such as Nick Fofonoff, Oleg Mamayev, Trevor McDougall, Frank Millero, Robert L. Smith, Matthias Tomczak and Jürgen Willebrand.

An improved potential version (Feistel and Hagen, 1995) addressed several weaknesses of its predecessor and of EOS80 , such as conversion to the ITS-90 temperature scale. Additional data were included to improve the equation in the vicinity of the temperature of maximum density (Caldwell, 1978; Siedler and Peters, 1986) and for deep-water sound speeds (Dushaw et al., 1993; Millero and Li, 1994). For a corrected asymptotic zero-salinity limit, the 1995 Gibbs function, $g^{\mathrm{SW}}$,

$$
\begin{aligned}
g^{\mathrm{SW}}\left(S_{\mathrm{P}}, T, p\right)= & g^{\mathrm{W}}(T, p)+g_{1}(T) S_{\mathrm{P}} \ln S_{\mathrm{P}}+g_{2}(T, p) S_{\mathrm{P}} \\
& +g_{3}(T, p) S_{\mathrm{P}}^{3 / 2}+\ldots
\end{aligned}
$$

recalculated the logarithmic ideal-solution term, $g_{1}$, and Debye's limiting law of dilute electrolytes, $g_{3}$, of the salinity expansion (Eq. 14) explicitly from an exactly electro-neutral chemical composition model of sea salt. As a precursor of the reference composition of TEOS-10 (Millero et al., 2008), this 1995 stoichiometry was a slightly modified version of that defined by Millero (1982). The new Gibbs function provided a reliable thermodynamic basis for the calculation of novel oceanographic tools such as conservative temperature (McDougall, 2003), of new efficient equations for numerical models (McDougall et al., 2003) and for the clarification of some misleading explanations for the adiabatic lapse rate (Eq. 8) given elsewhere (McDougall and Feistel, 2003).
Combined with a simple Gibbs function of ice (see Sect. 3.3), various properties of sea ice such as freezing point, melting heat and brine salinity could for the first time be calculated perfectly consistently with all other experimental data on seawater and ice involved (Feistel and Hagen, 1998).

Seawater properties are strongly related to those of the pure-water solvent, as given by the Gibbs function $g^{\mathrm{W}}$ in Eq. (14) and also indirectly by seawater properties measured with instruments that had been calibrated in advance using certain older, possibly inconsistent, pure-water equations. The extremely accurate Helmholtz function for pure water published by Wagner and Pruß (2002), the so-called IAPWS-95 equation (see Sect. 3.2), offered the chance for a fundamental update of the pure-water part of the 1995 Gibbs function of seawater. Moreover, it also suggested consistency corrections of the underlying experimental seawater data to be carried out with respect to their respective, obsolete pure-water references, as far as these dependencies could be inferred from the related publications. The resulting new Gibbs function for seawater (Feistel, 2003) was still expressed in terms of practical salinity. For the pure-water part, a Gibbs function had been fitted to IAPWS-95 over the oceanographic ranges of temperature and pressure. Updated ocean-model algorithms were derived from the 2003 equation by Jackett et al. (2006).

In contrast to quantities like heat capacity or specific volume, the sound speed expressed in terms of the Gibbs function (Eq. 7) is a complex non-linear formula in which the saline and the pure-water parts of the Gibbs function (Eq. 14) appear in several mathematical combinations. It is therefore not possible to simply "subtract" an obsolete "pure-water part" from seawater sound speed data and replace it by some improved values for the sound speed of pure water, as was done with the Gibbs function when IAPWS-95 was specified as its pure-water part. As Millero and Li (1994) reported, the problems encountered with Chen and Millero (1977) sound speeds resulted from the pure-water reference that Chen and Millero had used during their measurements. It turned out that a provisional a posteriori correction of that pure-water part by Millero and Li (1994) was not fully satisfactory because the required raw data were no longer available. Therefore, TEOS-10 has completely refrained from using Chen and Millero (1977) sound speed data and combined for the 2003 and 2008 Gibbs functions the Del Grosso (1974) sound speed with IAPWS-95 density for pure water and with seawater density and thermal expansion data as described in Feistel (2003). In the multi-property fit of the Gibbs function, this combination of data turned out to be mutually consistent and resolved the previous deviations found by Dushaw et al. (1993). Thus, while it appeared to be impossible to satisfactorily correct the experimental Chen and Millero (1976) data a posteriori by IAPWS-95, replacing those data by the sound speed of Del Grosso (1974) in the fit of the Gibbs function resolved the systematic problems encountered previously with the sound speed of seawater at high pressures. 
At that time, the various substantial advantages of the 2003 Gibbs function over the still valid EOS-80 standard, together with sophisticated new oceanographic tools such as conservative temperature, unavailable from EOS-80, sparked the idea of developing a new international seawater standard. In order to investigate this question, at the 2005 SCOR/IAPSO meeting at Cairns, Australia, "IAPSO had introduced a proposal for a new working group, and that was approved by SCOR as Working Group WG127 on Thermodynamics and Equation of State of Seawater. This work is expected to provide important input into modeling of the global ocean and, ultimately, climate change modeling" (IAPSO, 2005; SCOR, 2005). On the other hand, the Gibbs function of seawater was also presented at the 2005 annual IAPWS meeting at Santorini, Greece. The idea of developing an IAPWS equation for seawater was welcomed there and resulted in establishing an IAPWS Task Group on Seawater and in sending a letter to IAPSO expressing the IAPWS interest in working jointly on this problem (IAPWS, 2005).

Chaired by Trevor McDougall, WG127 held its inaugural meeting in 2006 at Warnemünde, Germany; see Appendix B. The WG confirmed the desirability of cooperating with the IAPWS on a jointly agreed seawater standard defined by a Gibbs function, suitable for both oceanographic and industrial applications, such as seawater desalination. IAPWS95 was adopted by WG127 as the pure-water reference for the future thermodynamics of seawater. Detailed numerical checks of the 2003 Gibbs function were initiated. For the standard ocean reference state $\left(S_{\mathrm{P}}=35, T=273.15 \mathrm{~K}\right.$, $p=101325 \mathrm{~Pa}$ ), the WG specified the entropy and enthalpy of seawater to vanish. The WG recommended the inclusion of additional available data at normal pressure (heat capacities, dilution heats, freezing points) for an extended Gibbs function.

The WG had an extensive discussion of absolute salinity, $S_{\mathrm{A}}$, the mass of solute per mass of solution; see Sect. 3.4. If the thermodynamic functions could be defined in terms of $S_{\mathrm{A}}$ instead of practical salinity $S_{\mathrm{P}}$, this would have the advantage that density calculated from the thermodynamic formulation would be a better fit to actual seawater density because it would reflect compositional changes. If defined by a fixed conversion factor for a reference composition, $S_{\mathrm{A}}$ is as accurate as $S_{\mathrm{P}}$ and fully compatible with present measuring techniques. $S_{\mathrm{A}}$ for a reference composition has an exact relation to traditional chlorinity. All physical, chemical and oceanographic, theoretical as well as numerical, models do actually rely on $S_{\mathrm{A}}$ rather than $S_{\mathrm{P}}$. Oceanography is the only scientific community that recognises various salinity variables other than $S_{\text {A }}$. Outside oceanography, salinity in technical and industrial applications (IAPWS) is traditionally understood as the amount of dissolved salt, which is absolute salinity, "total salinity" or "total dissolved solute" (TDS). The WG gave serious consideration to the idea that the fundamental oceanographic description should change from practical salinity to absolute salinity, but postponed decisions on this issue for its wide range of implications (McDougall et al., 2008). However, already in September 2006 some WG members started intense email activities around the clock and across complementary time zones around the globe aiming at the specification of a best estimate for the chemical composition of standard seawater.

In 2007, at the second WG127 meeting held in Reggio, Calabria (see Appendix B), draft articles had already been prepared regarding the reference composition (Millero et al., 2008) and an updated Gibbs function (Feistel, 2008a) based on that composition and expressed in terms of absolute salinity, $S_{\mathrm{A}}$, which for SSW equals the reference-composition salinity, $S_{R}$; see Eq. (11). While the pressure-independent part (responsible for freezing point, dilution heat, etc.) of the 2008 Gibbs function was significantly extended in its $T-S_{\mathrm{A}}$ validity range, the pressure-dependent part (responsible for density and its derivatives) remained identical to that of 2003. WG127 endorsed the use of the IAPWS 2006 Release on an equation of state for $\mathrm{H}_{2} \mathrm{O}$ ice Ih (IAPWS R10-06, 2009). Later, the new salinity definition and the 2008 Gibbs function were also presented at the 2007 IAPWS meeting at Lucerne, Switzerland. On this basis, a "Release on the IAPWS Formulation for the Thermodynamic Properties of Seawater" had been drafted for evaluation, with approval anticipated for 2008 (IAPWS, 2007).

While salinity rarely exceeds $40 \mathrm{~g} \mathrm{~kg}^{-1}$ in the global ocean, more concentrated brines are found, for example, in the lagoon-like Australian Shark Bay (up to $70 \mathrm{~g} \mathrm{~kg}^{-1}$; Logan and Cebulsk, 1970) and in particular in brine pockets of polar sea ice at low temperatures. Due to the latent heat contributions of melting or freezing pockets, the heat capacity of sea ice is significantly larger than that of either pure ice or seawater. Such high-salinity effects could properly be estimated by so-called Pitzer equations (Feistel and Marion, 2007), so there was a reasonable interest in also implementing this ability in TEOS-10. The new reference salinity scale supported this extension beyond the validity range of the previous practical salinity (see Sect. 3.4) and at the same time raised the question of the solubilities of the dissolved salts (Marion et al., 2009). It turned out that salinities up to $110 \mathrm{~g} \mathrm{~kg}^{-1}$ of Antarctic sea ice are well covered by the 2008 Gibbs function (Feistel et al., 2010a); see Fig. 4.

At the International Conference on the Properties of Water and Steam 2008 in Berlin, the 2008 Gibbs function was adopted as an IAPWS standard (IAPWS R13-08, 2008) in combination with the IAPWS-95 equation, which provides the pure-water part $g^{\mathrm{W}}(T, p)$ of Eq. (14) in implicit form. On the basis of mainly these two documents, TEOS-10 was endorsed by IOC/UNESCO in 2009 at Paris as a new international seawater standard "to replace EOS-80 and thus updating this valuable, but no longer state-of-the-art, 30-yearold UNESCO standard" (IOC, 2009, p. 5 therein; Wright et al., 2010b; IUGG, 2011; Valladares et al., 2011a, b). In Berlin, in addition to its four permanent working groups, the IAPWS established a new Subcommittee on Seawater that 


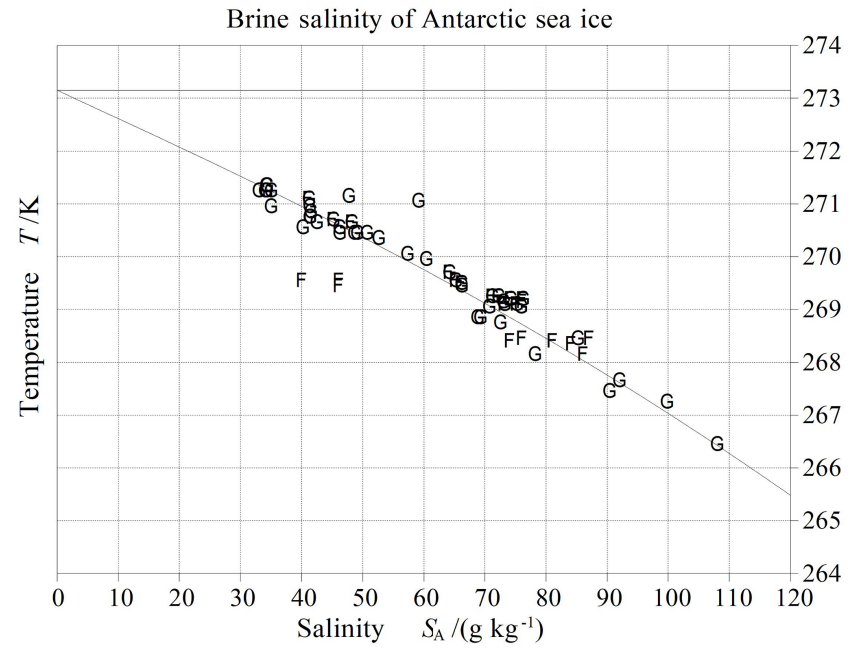

Figure 4. Brine salinity computed from TEOS-10 as a function of temperature at atmospheric pressure compared with measured results for brine pockets of Antarctic sea ice. Symbol "F": data of Fischer (2009); "G": data of Gleitz et al. (1995). As these observational data were not included in the construction of the 2008 Gibbs function, note that the curve is a theoretical prediction derived from the thermodynamic potentials of seawater and ice.

was suggested to consist of members from the SCOR/IAPSO WG127 and of other IAPWS members with interest in seawater problems (IAPWS, 2008).

The Gibbs function of seawater describes the thermodynamic properties at a homogeneous, gravity-free equilibrium state under pressure, without pressure gradients inside the volume. This idealisation matches the real ocean significantly better than a strict description of seawater at equilibrium under gravity. The latter would be characterised by pressure-dependent composition anomalies caused by barodiffusion of the salt species driven by the gradients of their unequal individual chemical potentials. In the real ocean, however, turbulent mixing is a substantially faster process than molecular diffusion, so no relevant pressure-induced chemical decomposition of sea salt is observed in practice (Fofonoff, 1962; Feistel, 2003; Feistel and Feistel, 2006; IOC et al., 2010, Appendix B therein). In this respect, although strictly speaking the ocean is in a permanent non-equilibrium state, thermodynamic conditions of the so-called "local equilibrium" (de Groot and Mazur, 1984) are almost perfectly met, supporting the oceanographic application of equilibrium thermodynamics in the form of a Gibbs function.

For industrial applications, two modifications of the 2008 Gibbs function for seawater were developed later. First, the validity of a new density equation (Feistel, 2010) at atmospheric pressure could be extended to temperatures up to $90^{\circ} \mathrm{C}$ and absolute salinities up to $70 \mathrm{~g} \mathrm{~kg}^{-1}$ using new measurements of Millero and Huang (2009). Second, for an industrial seawater standard the "scientific" Helmholtz function forming the pure-water part was replaced by an "indus- trial" IAPWS Gibbs function for liquid water (Wagner and Kretzschmar, 2008; Kretzschmar et al., 2015; IAPWS AN513, 2016).

The 2008 Gibbs function for seawater relies mainly on older experimental data from the 1960s and 1970s. Meanwhile, various new measurements of seawater properties, also under conditions outside the validity range of TEOS-10, have been published, such as density (Millero and Huang, 2009; Safarov et al., 2009, 2010, 2012, 2013) and sound speed (Millero and Huang, 2011; von Rohden et al., 2015, 2016; Lago et al., 2015). Further available data are reviewed by Sharqawy et al. (2010) and Nayar et al. (2016).

\subsection{Helmholtz function of humid air}

The flux of water across the ocean-atmosphere interface belongs to the most important processes of the global climate system, but its estimated contribution to the total heat loss of the ocean varies greatly between $50 \%$ (Emery et al., 2006) and $90 \%$ (Wells, 2012). The thermodynamic driving force for evaporation is the difference between the chemical potentials of water in seawater and in humid air. Usually, this difference is approximated by the relative humidity of air (Kraus and Businger, 1994). This estimate is known to be in error by typically $2 \%$ because of the lowered vapour pressure of seawater compared to that of pure water. To get an idea of the relevance of this error, note that a small change in the global latent heat flux by $1 \%$, or about $1 \mathrm{~W} \mathrm{~m}^{-2}$, would exceed by a factor of 200 the flux responsible for the currently observed greenhouse warming of the atmosphere, about $0.005 \mathrm{~W} \mathrm{~m}^{-2}$ (Lovell-Smith et al., 2016; Feistel, 2015, 2017). The estimated energy imbalance of $0.4-0.8 \mathrm{~W} \mathrm{~m}^{-2}$ of the warming ocean (Cheng et al., 2016) is also within this error range. However, on the other hand, routine meteorological measurement of relative humidity has a typical uncertainty between 1 and 5\%rh (Lovell-Smith et al., 2016), thus being insufficient to observe those climatically crucial heat flux anomalies.

In order to also consistently include in TEOS-10 the thermodynamic properties of the air-sea interface, such as the latent heat of evaporation or relative humidity at equilibrium with seawater, the first intention was to simply adopt a thermodynamic potential for humid air from the scientific literature. Unfortunately, as it turned out, such a function had never been developed by the atmospheric and humidity communities. Similar to the situation with seawater, only certain collections of separate empirical property equations of unclear mutual consistency were available (Goff and Gratch, 1945; Sonntag, 1966; Linke and Baur, 1970; Gill, 1982; Gatley, 2005; Murphy and Koop, 2005; WMO, 2008). So it was necessary to construct a new TEOS-10 Helmholtz function for humid air, $f^{\mathrm{AV}}$, from a minimum number of available, mutually independent but internally consistent, empirical de facto standard functions: 


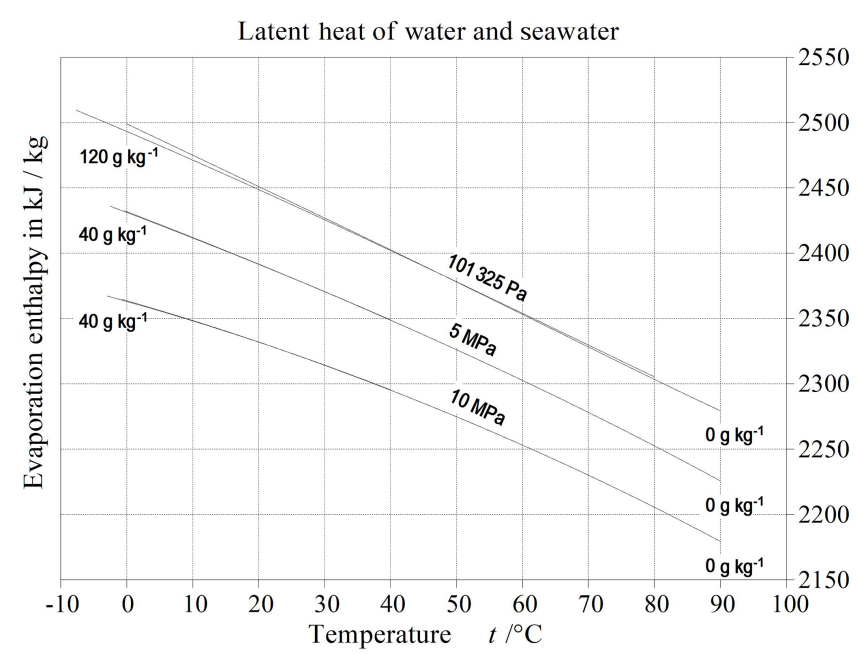

Figure 5. Isobaric evaporation enthalpy of water, indicated by " $0 \mathrm{~g} \mathrm{~kg}^{-1}$ ", and of seawater with salinities of $120 \mathrm{~g} \mathrm{~kg}^{-1}$ at $101325 \mathrm{~Pa}$ and $40 \mathrm{~g} \mathrm{~kg}^{-1}$ at $5 \mathrm{MPa}$ and $10 \mathrm{MPa}$ as functions of the temperature and computed from TEOS-10. Here, the latent heat of evaporation of seawater is derived from the total heat capacity of a two-phase seawater-air composite, reduced by the two separate single-phase heat capacities involved. The salinity corrections to the latent heats of pure water are very small. At high pressure the validity of the Gibbs function of seawater is restricted to maxima of $40 \mathrm{~g} \mathrm{~kg}^{-1}$ and $40^{\circ} \mathrm{C}$, but at atmospheric pressure it is valid up to $120 \mathrm{~g} \mathrm{~kg}^{-1}$ and $80^{\circ} \mathrm{C}$. The lower temperature bounds shown are the particular freezing points of water or seawater (Feistel et al., 2010b).

$$
\begin{aligned}
f^{\mathrm{AV}}(A, T, \rho)= & A f^{\mathrm{A}}(T, A \rho)+(1-A) f^{\mathrm{V}}(T,(1-A) \rho) \\
& +A(1-A) f^{\mathrm{mix}}(A, T, \rho) .
\end{aligned}
$$

Here, $A$ is the mass fraction of dry air in humid air, $\rho$ is the mass density of humid air, $f^{\mathrm{A}}$ is the Helmholtz function of dry air of Lemmon et al. (2010), $f^{\mathrm{V}}$ is the IAPWS95 Helmholtz function of water vapour (see Sect. 3.2) and $f^{\text {mix }}$ consists of second (Harvey and Huang, 2007) and third (Hyland and Wexler, 1983) cross-virial coefficients for airwater interaction. Equation (15) and some resulting properties, such as the latent heat of evaporation of seawater (see Fig. 5) and the entropy of clouds (see Fig. 6), were first discussed at the 2009 meeting of WG127 at Arnhem, the Netherlands; see Appendix B. In 2010, the Helmholtz function (15) for humid air was eventually adopted as an official IAPWS formulation at Niagara Falls, Canada (IAPWS G810, 2010; Feistel et al., 2010b), and presented at the Portorož symposium on temperature and humidity metrology (Feistel, 2012).

In their common ranges of validity, the IAPWS equation of humid air is consistent with the metrological high-accuracy CIPM-2007 equation (Picard et al., 2008) for the density of humid air. Picard et al. (2008) outline previous problems with the molar mass of dry air, which also differs slightly between the equations of Feistel et al. (2010b) and IAPWS G8-10 (2010). Unlike the original definition of Lemmon et al. (2010), the TEOS-10 equation for dry air specifies zero entropy and zero enthalpy of dry air at the standard ocean surface, $0^{\circ} \mathrm{C}$ and $101325 \mathrm{~Pa}$, as reference-state conditions. Ideal-gas approximations and their related adjustable constants, consistent with TEOS-10, are reported in Feistel et al. (2010b). For most atmospheric applications, small corrections to the ideal-gas equations in the form of virial coefficients are sufficiently accurate. For this purpose, from Eq. (15) a numerically more convenient virial Gibbs function of humid air can be derived (Feistel et al., 2015; IAPWS G11-15, 2015). A recent review of thermodynamic equations for humid air properties is given by Herrmann et al. (2017).

\section{Extracting properties from TEOS-10}

The four fundamental thermodynamic potentials of TEOS10 (see Fig. 7) as described in Sect. 3 possess axiomatic properties of consistency, independence and completeness. An axiomatic approach to formally defining and representing all thermodynamic properties with respect to a minimum common set of basic functions may avoid confusion, may more easily permit identification and quantification of differences between seemingly equivalent quantities such as various alternative definitions of relative humidity, and may establish solid thermodynamic links between quantities that were originally introduced separately and independently (Feistel et al., 2016), such as correlation equations for the heat capacity and for the sublimation pressure of ice; see Sect. 3.3.

In thermodynamics, it is often possible to express a certain (unknown) quantity in terms of a combination of other (known) quantities. In any of such exact relations, if all the properties involved are expressed in terms of the same thermodynamic potential, the final formula for the target quantity will always be the same. This rigorous, convenient fundamental feature is regarded as the consistency property of a thermodynamic potential. By exploiting alternative thermodynamic relations it is impossible to derive from TEOS10 different results for one and the same thermodynamic quantity. Maxwell's cross relations between different quantities are always identically fulfilled, rather than just approximately. In contrast, previous collections of separate property equations are not necessarily consistent. As an example, from the EOS-80 collection (Unesco, 1983) one can compute the heat capacity directly from one given equation, but also indirectly from the additionally given equations for density and sound speed. The corresponding two results differ, even drastically near the temperature of maximum density.

The axiomatic property of independence expresses the fact that no part of the four fundamental potentials of TEOS-10 may be derived from other parts. In particular, if a more accurate update is available for any of those parts, independence 
(a) Entropy bounds of wet air

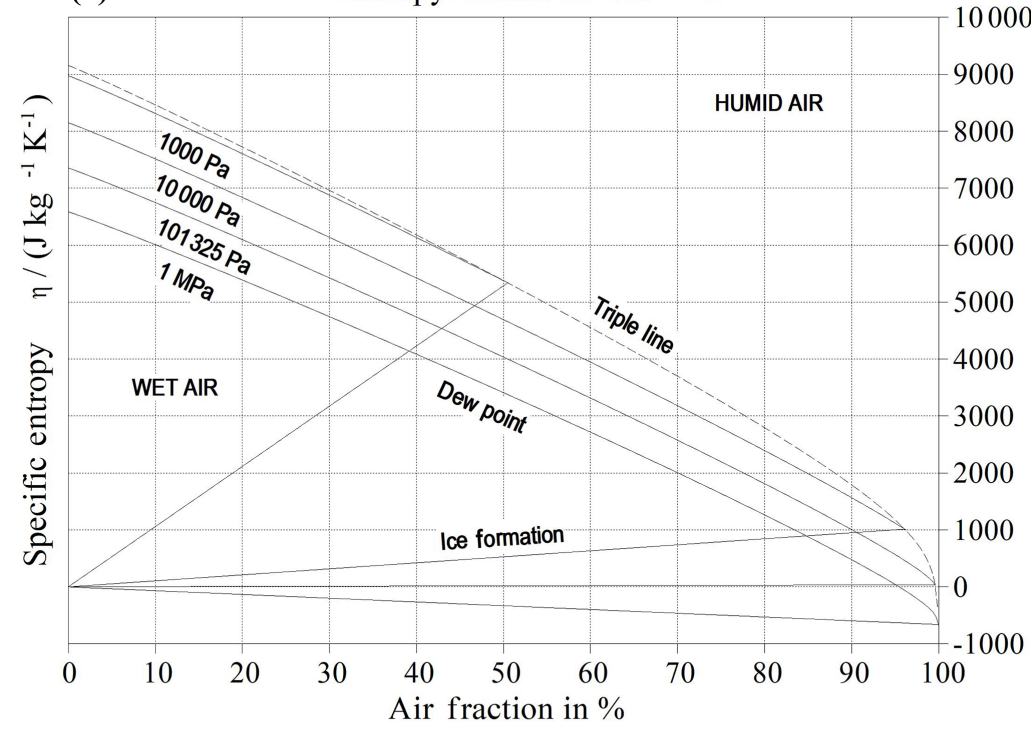

(b)

Entropy bounds of wet ice air

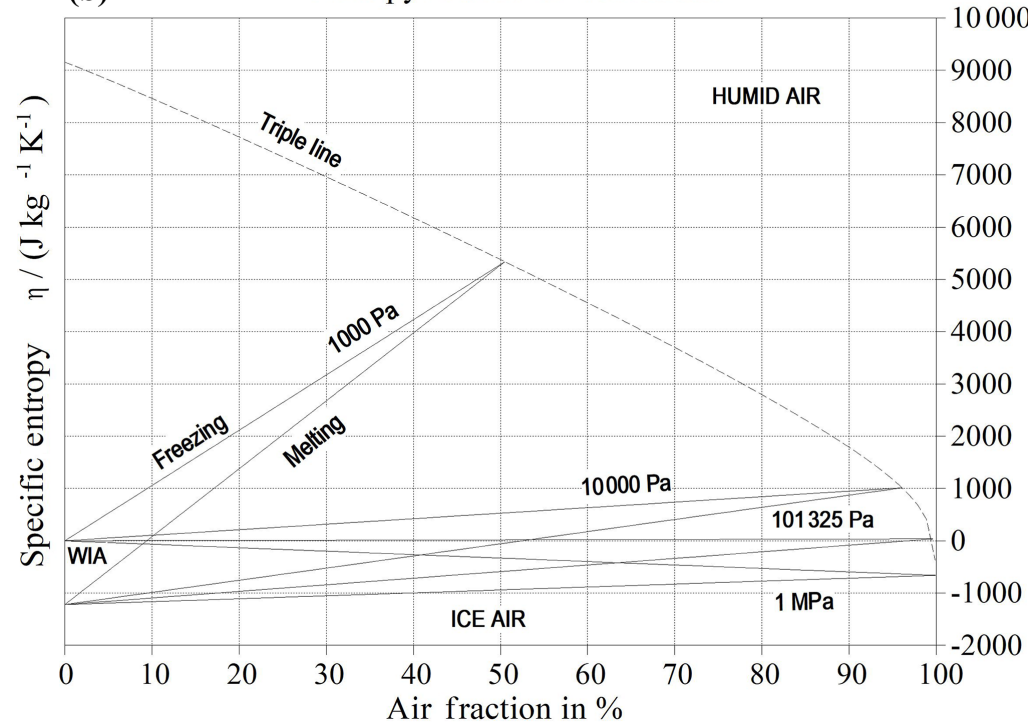

Figure 6. Phase diagrams of composite air-water-ice systems ("clouds"), depending on the entropy and dry-air mass fraction of a given parcel, computed from TEOS-10 (Feistel et al., 2010a). Natural clouds with air fractions of 98-99\% at pressures between 20000 and $101325 \mathrm{~Pa}$ are located in the lower right corner of the diagrams. Metastable states, such as subcooled liquid droplets (WMO, 2008), are not considered here. (a) In the triangle-shaped, two-phase regions "wet air", humid air is in equilibrium with liquid water. The tips of these wetair wedges are triple points located along the "triple line" depending on the pressure (or altitude) as indicated. Above the wedge, between the "dew point" curve and "triple line", humid air is the only stable phase. Between "dew point" and "ice formation", liquid water is in equilibrium with humid air. (b) In the triangle-shaped, three-phase regions "WIA" (wet ice air), humid air is in equilibrium with both liquid water and ice at the same time. The tips of these WIA wedges are triple points located along the "triple line" depending on the pressure (or altitude) as indicated. Above the wedge, the cloud contains only liquid water (wet air), if at all, while below the wedge, ice is the only condensed stable phase (ice air) in equilibrium with humid air.

When adiabatically ascending, the entropy and dry-air fraction of an air parcel remain unchanged, even when passing the transition to cloud formation (the isentropic condensation level), and so does the parcel's representative point in the diagrams. With decreasing pressure, the "wet-air" and "wet-ice-air" regions will pan to the left, and states located initially between the "dew point" and "triple line" get into the wetair region first, then become wet ice air, and finally ice air. Points located above the "triple line" condensate to ice directly without passing any intermediate liquid phase. Using such diagrams, the parcel's phase changes during convection may be predicted from its conservative properties at the ground. 


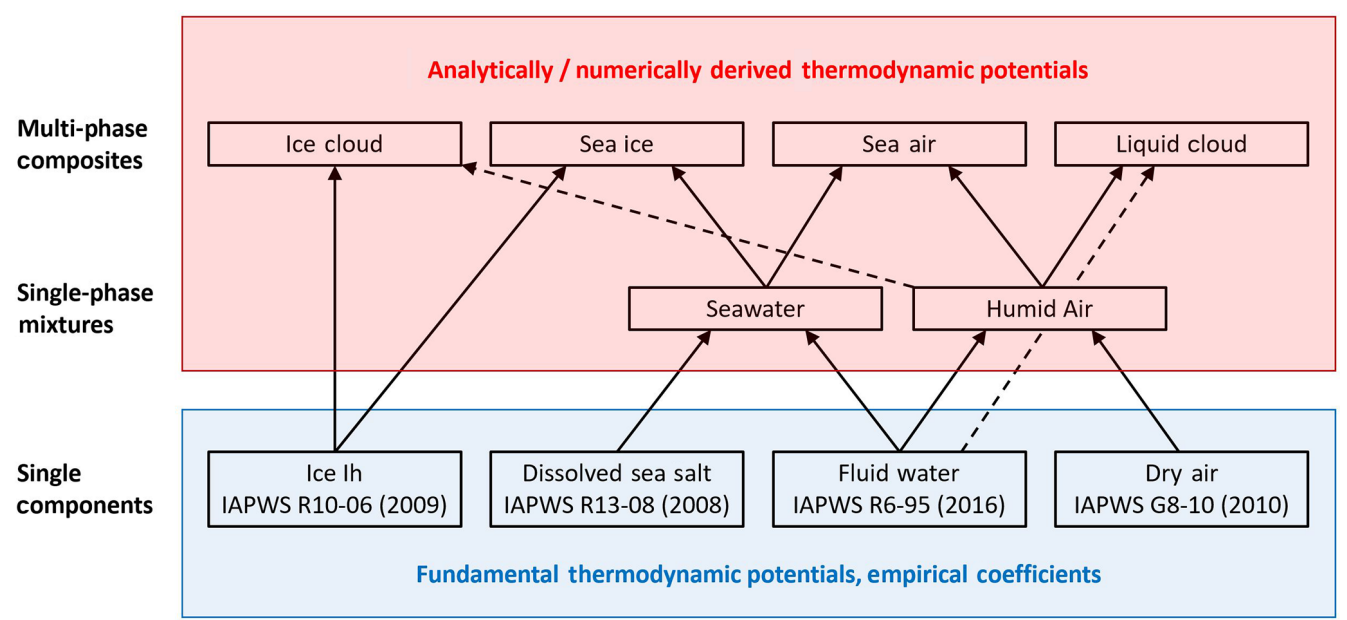

Figure 7. Hierarchical structure of TEOS-10 based on four fundamental thermodynamic potentials defined in IAPWS documents for ice Ih, fluid water, dissolved sea salt and dry air, including air-water interaction properties. Derived from those fundamental equations and their empirical coefficients by numerical and analytical mathematical methods without introducing any additional empirical functions or coefficients, any thermodynamic properties can be computed for the pure substances (such as water and ice), their mixtures (such as seawater and humid air) and multi-phase composites (such as sea ice, ocean-atmosphere equilibria and clouds).

permits replacing an obsolete part without adjustments to be made for the other parts. In contrast, previous collections of separate property equations are not necessarily independent. As an example, the EOS-80 equation for the pressure dependence of the heat capacity is related by a Maxwell relation to the temperature dependence of the density. It is therefore not advisable to update one equation of such a collection without carefully considering any possible side effects this may have on the other equations.

The third axiomatic property, completeness of thermodynamic potentials, was discovered by Gibbs; see the quotation in the Abstract. As soon as for a given equilibrium system a thermodynamic potential is available, no matter which one (see Sect. 2), all its thermodynamic properties can be derived by merely mathematical manipulations. The system may even be a chemically reacting one or a multi-phase composite. In contrast, previous collections of separate property equations are not necessarily complete. As an example, the EOS-80 collection does not provide the entropy, enthalpy or chemical potentials of seawater.

Note, however, that there are some minor, usually irrelevant, exceptions to these general rules in TEOS-10. For example, the thermodynamic potentials are not perfectly consistent as they use slightly different values for the molar gas constant that were the international reference values at the time the particular equation was developed. The thermodynamic potentials are not entirely independent as they commonly depend, for example, on the definition of the temperature scale (see Sect. 3.1) and on the definitions of referencestate conditions (see Sect. 2). Completeness does not apply to, say, the sound speed in ice, which is typically anisotropic in crystalline solid states, while the TEOS-10 equation describes ice as an isotropic substance.

Mathematical formulas for the computation of numerous quantities are derived and explained in the TEOS-10 manual (IOC et al., 2010) and in several IAPWS documents supporting TEOS-10 (IAPWS AN6-16, 2016). Large subsets of those quantities are implemented in two open-source libraries, the Sea-Ice-Air (SIA) library (Feistel at al., 2010a; Wright et al., 2010a), and the Gibbs Seawater (GSW) library (McDougall and Barker, 2011; McDougall et al., 2012; Roquet et al., 2015). Source code in several programming languages is freely available from the TEOS-10 web site at www.teos-10.org (last access: 8 June 2018).

In the SIA library, thermodynamic potentials are numerically available for single-phase and multi-phase systems such as those displayed in Fig. 7, together with various properties such as the heat capacities, densities and entropies of those systems. As a first step, for a convenient calculation of properties at given temperature, pressure and composition, Gibbs functions are implemented for seawater, $g^{\mathrm{SW}}\left(S_{\mathrm{A}}, T, p\right)$, and humid air, $g^{\mathrm{AV}}(A, T, p)$, together with nine additional functions each, for any of their first and second partial derivatives. For this purpose, equations for pressure as a function of the density, $p=\rho^{2}(\partial f / \partial \rho)$, available from the Helmholtz functions (see Sect. 2) must be inverted iteratively to find the density as a function of the given pressure. The specific entropy, $\eta$, of a sample with given in situ temperature $T$ at pressure $p$ is then available from the related Gibbs function by evaluating $\eta=-\partial g / \partial T$. As a second step, enthalpies $h^{\mathrm{SW}}\left(S_{\mathrm{A}}, \eta, p\right)$ and $h^{\mathrm{AV}}(A, \eta, p)$ of seawater and humid air, respectively, are implemented by executing another numerical iteration procedure. From those functions, for a given ref- 
erence pressure $p_{\text {ref }}$, potential enthalpy, $h_{\theta}=h\left(\eta, p_{\text {ref }}\right)$, potential temperature, $\theta=\partial h\left(\eta, p_{\text {ref }}\right) / \partial \eta$, and potential density, $\rho_{\theta}^{-1}=\partial h\left(\eta, p_{\text {ref }}\right) / \partial p$, can be computed. Note that all input and output quantities of the SIA library are expressed in basic SI units, such as temperatures in $\mathrm{K}$ (rather than ${ }^{\circ} \mathrm{C}$ ), pressures in $\mathrm{Pa}$ (rather than dbar relative to the surface pressure), and salinity or dry-air fraction in $\mathrm{kg} \mathrm{kg}^{-1}$ (rather than in psu or $\mathrm{g} \mathrm{kg}^{-1}$ or \%). This strict convention avoids the need for any unit conversions along with the various mathematical manipulations performed internally. Such conversions are error-prone; to see this, imagine modifying the sound speed formula (7) for the case in which pressure is measured in decibars rather than pascals.

Similar to the potential functions and properties of singlephase systems, the SIA library also implements the Gibbs functions and enthalpies of composite systems, such as sea ice consisting of seawater and ice or clouds consisting of liquid water and humid air, at their mutual thermodynamic phase equilibria. The SIA library is organised in the form of several separate modules. It is possible to select an axiomatic subset of such modules as a sub-library, such as one just for ice or one for humid air, as discussed in the digital Supplement of Feistel et al. (2016). It is also possible to combine SIA modules with additional user-defined modules for, say, specific functions that do not yet belong to the standard library set. For example, such add-ons may be developed for including the effects of dissolved air on water properties which are currently neglected in TEOS-10.

For frequent calls within ocean models, the stacked iterations of the SIA library are too slow, and the variables and their units are inconvenient. For these reasons, the GSW library implements fast and tailored equations in terms of appropriate input parameters, accepting oceanographically familiar units, such as pressure in decibars, absolute salinity in grams per kilogram and conservative temperature as potential enthalpy expressed in ${ }^{\circ} \mathrm{C}$. The price for this advantage is the introduction of new empirical equations with additional regression coefficients obtained by fitting with respect to data calculated from the SIA library equations. Potential future updates of any fundamental TEOS-10 equation (see Fig. 7) will automatically propagate into the various derived SIA functions, but will require updated sets of coefficients of the GSW library. Detailed descriptions of the oceanographic quantities and their use in the context of TEOS-10 are available from IOC et al. (2010), McDougall and Barker (2011), McDougall et al. (2013) and Roquet et al. (2015).

\section{Problems beyond TEOS-10}

TEOS-10 was developed as a state-of-the-art thermodynamic framework supporting geosciences in their tasks of observing, understanding, modelling and predicting the global climate system and its long-term variations. Successful cooperation between climate-related research groups anywhere on the planet, extending over several human generations, demands mutual comparability of their respective individual theoretical and measurement results. This indispensable requirement appears to be self-evident, but unfortunately it is by no means always fulfilled yet, and in certain cases it even poses a serious challenge still to be addressed in the future. All relevant quantities should be uniformly defined, preferably by commonly agreed international standards or recommendations. All measurement results of the same kind of quantity should be metrologically traceable to the same reference, preferably specified as an international standard of the highest temporal stability. The actual quantities of interest, such as seawater salinity, should be related to their associated measurands, such as temperature and conductivity, by standard equations of certified estimated uncertainty. Related pending problems were presented and discussed at the 2010 WMO-BIPM workshop entitled Measurement Challenges for Global Observation Systems for Climate Change Monitoring in Geneva, Switzerland (WMO, 2010).

According to the rules for SCOR/IAPSO working groups, WG127 was disbanded in 2011 (Pawlowicz et al., 2012). During the development of TEOS-10, relevant problems had become visible regarding the definitions of seawater salinity, seawater $\mathrm{pH}$ and the relative humidity of moist air. In order to address these problems along with maintaining TEOS-10, a standing Joint Committee on the Properties of Seawater, JCS, was established by SCOR, IAPSO and the IAPWS in 2012 (IAPWS, 2012). At the BIPM at Sèvres in 2011 and 2012, related meetings on a potential future cooperation took place, and subsequently a joint workshop of JCS was held with representatives of the BIPM at the 2013 International Conference on the Properties of Water and Steam in Greenwich, UK (Feistel, 2013; IAPWS, 2013; Hellmuth et al., 2014; Pawlowicz et al., 2014; Feistel et al., 2016). Recent progress and upcoming tasks are planned to be on the agenda of the 2018 International Conference on the Properties of Water and Steam in Prague, Czech Republic.

\subsection{Seawater salinity}

During the development of TEOS-10, much attention was paid to the question of how salinity should be defined in oceanography (McDougall et al., 2008; Millero et al., 2008; Seitz et al., 2011; Wright et al., 2011; Pawlowicz et al., 2016). In current practice, salinity measurement is performed by electronic sensors for pressure, temperature and conductivity. Those sensors usually consist of some arrangement of electronic devices, such as a platinum resistor, and typically return signals in the form of an electric voltage, a current or a frequency. In a calibration lab, the sensor is immersed in seawater of well-defined conditions, and its output signal values are associated with the particular temperatures, pressures or salinities of the bath. To establish those well-defined conditions, the lab needs to measure the bath temperature and to use seawater samples of certified salinities. The lab's ther- 
mometers are regularly calibrated against temperature standards realised in national metrological institutes, which in turn implement the rules specified for the ITS-90 definition of the kelvin within the International System of Units (SI). Certified standard seawater samples are commercially produced and distributed by the IAPSO Standard Seawater Service operated by OSIL, Ocean Scientific International Ltd., a company located near Portsmouth, UK. At OSIL, seawater samples collected from the North Atlantic are purified, diluted and compared against the conductivity of a potassium chloride $(\mathrm{KCl})$ solution as specified by the 1978 Practical Salinity Scale.

These chains of calibration procedures establish the socalled metrological traceability of measurement results (de Bievre and Günzler, 2005; Seitz et al., 2011; VIM3, 2012). Traceability to the same primary reference is a necessary condition for the comparability of measured values from different devices at different locations or times. While temperature measurement is traceable to the SI, salinity is traceable to manufactured, possibly varying or ageing, artefacts in the form of certain $\mathrm{KCl}$ solutions or certified SSW batches. Although consistent with the SI (Unesco, 1985; Siedler, 1998), PSS-78 and consequently the new reference-composition salinity of TEOS-10 are metrologically not traceable to the SI (Seitz et al., 2010, 2011; Pawlowicz et al., 2016).

For long-term series such as those required for climate research, the temporal stability of the primary references is of ultimate relevance. It must be granted that tiny trends in observed values constitute real changes rather than just spurious effects caused by drifts of measurement devices or standards. In order to achieve the highest metrological stability available, traceability to the SI is the preferred choice. However, traceability to the SI is of sufficient advantage only if the related measurement uncertainty is small enough. For example, absolute conductivity measurements are traceable to the SI, but their uncertainty is about 1 order of magnitude too large compared to the PSS-78 standard, and defining salinity by a specified conductivity number rather than by a mass fraction of a reference $\mathrm{KCl}$ solution would in practice let small but significant observed salinity trends disappear in point clouds of noisy scatter. Based on such arguments, after many long and memorable discussions, the 2008 meeting of WG127 at Goetz near Berlin (see Appendix B) came to the conclusion that currently seawater density is the only promising candidate for SI-traceable salinity measurements in oceanographic practice (Seitz et al., 2011; Wright et al., 2011; Pawlowicz et al., 2016). No other seawater property has been demonstrated so far to be practically measurable with requisite accuracy and to be traceable to the SI at the same time.

TEOS-10 has already established density measurement as a secondary method for the determination of absolute salinity in cases of expected seawater composition anomalies (Millero et al., 2008; Feistel at al., 2010c); see Sect. 3.4. The concept recently developed by JCS (Pawlowicz et al., 2016) aims at a specification of certified standard seawater samples not only by their practical salinities as presently, but in the future also in parallel by their densities, measured in a way that is traceable to the SI. This approach would leave current oceanographic practice unaffected but could grant the requisite long-term stability of the SSW standard for the very first time after SSW was introduced by Knudsen more than a century ago (Knudsen, 1903; Wallace, 1974; Culkin and Smed, 1979; Burchard et al., 2018). While this concept will not in any way make IAPSO Standard Seawater samples "more stable" than currently, it offers a so-far unavailable option of measuring (and correcting for) suspected long-term (century scale) changes in the reference material against an ultimately stable metrological reference. It also directly supports the use of density salinity as the key salinity variable describing seawater; see Sect. 3.4.

Although the intended new salinity definition appears physically and metrologically sound, there are a large number of detailed technical, metrological, logistical and financial questions and problems that need to be addressed before a new international, density-based salinity standard may be introduced officially (Pawlowicz et al., 2016; Schmidt et al., 2016, 2018). Among the related research tasks of JCS is finding an explanation for unexpected systematic negative density anomalies like those displayed in Fig. 3. Anomalies of similar magnitude have meanwhile been found in various regions of the world ocean (Budéus, 2018) and even in some (but not all) certified SSW samples (Feistel et al., 2010c, Fig. 6 therein). So far, the reasons remain elusive; working hypotheses may include unknown chemical (possibly organic) composition anomalies, isotopic composition anomalies of pure water, previously unnoticed bias in background data of TEOS-10, sample pollution such as by microplastic or measurement errors of other unknown origin. Only after the collection and analysis of more data and the discovery of responsible causes may conclusions be drawn and implemented in the future.

Currently, state-of-the-art density measurements of seawater samples collected at sea by bathysonde bottles may be performed with requisite accuracy by using vibrating-tube density meters. Such instruments work under laboratory conditions at well-known air pressure and stabilised ambient temperature on-board a vessel or, after the cruise, on land (Kremling, 1971; Millero et al., 1976, 2008, 2009; Feistel et al., 2010c; Budéus, 2018). Careful and experienced sample manipulation is crucial for reliable results (Schmidt et al., 2016); a related "best practice" manual is in preparation by JCS. Using the equation of state, the in vitro results are transferred to the sample's original in situ conditions of known pressure, temperature and practical salinity. Regional in situ gravity conditions affect the local pressure via the hydrostatic equation but are largely irrelevant if the in situ pressure itself is measured rather than computed (see also Sect. 3.5). In situ density sensors mounted at bathysondes are desirable but presently existing prototypes suffer from insufficient resolution. Similar to the PSS-78 standard, which specifies a stan- 
dard equation for the conversion of measured triples of pressure, temperature and conductivity ratio to practical salinity, the related standard equation for the density-salinity conversion could be the TEOS-10 equation of state, as already implemented in the SIA and GSW software libraries.

\subsection{Seawater $\mathbf{p H}$}

As a marine chemistry quantity, the $\mathrm{pH}$ of seawater does not belong to the thermodynamic properties available from the equations of TEOS-10, but connections between them were on the agenda of WG127 already in 2007 at Reggio (see Appendix B) and at later meetings. As an urgent problem beyond TEOS-10, seawater $\mathrm{pH}$ belongs to the climatological key parameters depicted as metrological challenges by JCS, the successor of WG127 (Feistel et al., 2016; Dickson et al., 2016). For suspectedly disastrous effects on marine ecosystems, the acidification of the oceans quantified in terms of seawater $\mathrm{pH}$ values, has become a severe public, ecological and political concern (Feely et al., 2004; Le Quéré et al., 2015) far beyond mere curiosity of a few scientists. However, the inventor of the $\mathrm{pH}$ value, Sören Peter Lauritz Sörensen, had already lamented the ambiguous measurement methods in use for seawater $\mathrm{pH}$. "So wäre es zu wünschen, daß man zukünftig bei der Bestimmung ... immer von denselben Voraussetzungen ausgeht, oder jedenfalls daß die Grundlage des angewandten Verfahrens scharf pointiert wird" (Sörensen and Palitzsch, 1910, p. 415 therein; English translation: "It is desirable that future estimates ... be always based on the same assumptions, or at least that the method applied be precisely described"). Unfortunately, over the past century this situation has improved only insignificantly. Different seawater $\mathrm{pH}$ scales are in practical use, often denoted by simply " $\mathrm{pH}$ ", which may deviate from one another more strongly than the expected variations to be resolved (Marion et al., 2011; Spitzer et al., 2011; Brewer, 2013; Dickson et al., 2016). Indeed, "the field of $\mathrm{pH}$ scales and the study of proton-transfer reactions in seawater is one of the more confused areas of marine chemistry" (Dickson, 1984).

Originally, Sörensen (1909) defined the $\mathrm{pH}$ value of an aqueous solution as the negative common logarithm of the hydrogen-ion concentration expressed in moles per litre. To better account for the effects of ionic interactions in the solution, in this definition equation the concentration was later replaced by the hydrogen-ion activity, specified in a way that both definitions coincide asymptotically in the idealsolution approximation (Sørensen and Linderstrøm-Lang, 1924). However, even without application to seawater in particular, these definitions involve two severe physico-chemical and metrological difficulties.

The first problem is that physically any distinction between a free (dissociated) ion and a bound (associated) ion is subject to arbitrary convention (Bjerrum, 1926; Falkenhagen et al., 1971; Ebeling and Grigo, 1982; Justice, 1991). Consequently, direct measurements of the ion concentrations of incompletely dissociated solutions are impossible unless the underlying convention is somehow embodied in the measurement procedure. What in fact can be measured are certain properties correlated with ion concentrations, such as the colour of an indicator dye by photometric $\mathrm{pH}$ methods. For obtaining the quantity of interest $(\mathrm{pH})$ from the quantity actually measured (colour), a calibration relation is required which implicitly or explicitly implements the particular ionassociation convention, similar to the ticks on a mercury thermometer that implement the definition of the Celsius scale in terms of length units. However, the requisite $\mathrm{pH}$ convention is still pending.

The second problem is that single-ion activities cannot be measured either (Bjerrum, 1919; Guggenheim, 1949), nor can they unambiguously be inferred from the mean chemical potentials of electrically neutral combinations of ions. To overcome this problem, auxiliary assumptions are sometimes applied, such as equating the activities of cations and anions of a particular solute, as suggested for $\mathrm{KCl}$ by Lewis and Randall (1923). Such arbitrary practical "conventions" may reasonably be applied as long as they do not conflict with experimental evidence. On the other hand, in contrast to empirical thermodynamics, in the statistical thermodynamics of electrolytes the Debye-Hückel limiting law predicts the single-ion activity to be a well-defined function of the ionic strength of very dilute electrolytes (Falkenhagen et al., 1971; Prausnitz et al., 1999). Theoretical relations of this kind between activities and other measurable quantities, such as equations for single-ion activities derived from Pitzer equations, are at odds with the putative validity of artificially constructed conventions.

Beyond the limiting law, analytical expressions for singleion activities or related analytical expressions are only approximately available for dilute solutions (below $1 \mathrm{~mol} \mathrm{~L}^{-1}$ ) in the theoretical framework of the statistical thermodynamics of electrolytes (Wiechert et al., 1978; Ebeling and Scherwinski, 1983). At ion concentrations such as $1.2 \mathrm{~mol} \mathrm{~kg}^{-1}$ typically encountered in the ocean (Feistel and Marion, 2007), convenient simplifying theoretical models, such as hard spherical ions immersed in an unstructured background solvent, become increasingly inappropriate. The real microscopic interactions of electrolytes are not precisely known and can only approximately be represented mathematically. A workable practical approach to this problem may be the use of so-called Pitzer equations. They approximate singleion activities as series expansions with respect to the ion concentrations and adjust the unknown empirical coefficients to other measurable properties (Nesbitt, 1980; Marion and Grant, 1994; Prausnitz et al., 1999; Marion and Kargel, 2008; Marion et al., 2011). Pitzer equations for seawater ions successfully describe colligative properties, while other thermodynamic properties such as sound speed may not yet be represented as accurately as by TEOS-10 (Feistel and Marion, 2007; Feistel, 2008a; Sharp et al., 2015). Based on the reference-composition model of TEOS-10 (Millero et al., 
2008), studies are underway aiming at a definition of seawater $\mathrm{pH}$ in terms of Pitzer equations as functions of SItraceable measurands (Waters and Millero, 2013; Dickson et al., 2016; Turner et al., 2016; Camões et al., 2016).

\subsection{Relative humidity}

In TEOS-10, equations for two different definitions of relative humidity (RH) are provided: the "WMO definition" and the "CCT definition" (IOC et al., 2010; Feistel et al., 2010a, b; IOC et al., 2010). These choices made for both names turned out to be misleading, unfortunately. The socalled WMO definition was taken over from recent textbooks on atmospheric sciences (Gill, 1982; Rogers and Yau, 1989; Pruppacher and Klett, 1997; Jacobson, 2005; Pierrehumbert, 2010); however, the definition reported in those books incorrectly retains an obsolete definition of the OMI (1951), which was superseded by the current WMO definition in 1954. What is called the CCT definition in TEOS-10, on the other hand, is in fact the current WMO definition (WMO, 2008), while the Consultative Committee on Thermometry (CCT) of the BIPM has not yet recommended any RH definition. Subsequently, closer inspection showed that this regrettable naming confusion in TEOS-10 reveals only the "tip of the iceberg" (Lovell-Smith et al., 2016). Several mutually inconsistent definitions of relative humidity prevail in different branches of meteorology, climatology, physical chemistry, food engineering and air conditioning, all of them typically denoted by just "RH" without additional specification.

The global ocean surface presents a vast open window to the very heart of the dynamics governing the climate system. Properties and processes may be observed there by research vessels, automatic buoys and remotely sensing satellites over long times with exceptional spatial coverage. On the other hand, clouds, wind, waves, corrosive and depositing sea salt, floating icebergs, plastic garbage or oil spills, commercial ship traffic and fishery, sensor fouling by biological processes, political, economic and military interests of riparian states, and large distances and high costs for device maintenance may pose severe difficulties for systematic scientific investigations of the air-sea interface at the open ocean. While TEOS-10 cannot overcome such practical obstacles, it has been developed with the intention of providing a consistent thermodynamic framework for studies of the transfer of energy and water between ocean and atmosphere as key players of the terrestrial climate.

Water in the troposphere has a mean residence time of $8-10$ days until it precipitates as rain or snow. About 80 to $90 \%$ of that water is replaced by evaporation from the oceans (Reid and Valdés, 2011). Evaporation is driven by the difference between the chemical potentials of water in humid air and in seawater or ice. Per mass of water, these chemical potentials are available from TEOS-10: for humid air from the Helmholtz function (15) by the relation (IAPWS G8-10,
2010)

$\mu_{\mathrm{W}}^{\mathrm{AV}}=f^{\mathrm{AV}}+\rho \frac{\partial f^{\mathrm{AV}}}{\partial \rho}-A \frac{\partial f^{\mathrm{AV}}}{\partial A}$,

for seawater (and in the limit $S_{\mathrm{A}}=0$, also for pure liquid water) from the Gibbs function (14) by the relation (IAPWS R13-08, 2008)

$\mu_{\mathrm{W}}^{\mathrm{SW}}=g^{\mathrm{SW}}-S_{\mathrm{A}} \frac{\partial g^{\mathrm{SW}}}{\partial S_{\mathrm{A}}}$

and for ice from its Gibbs function, $g^{\text {Ih }}$, by the relation (IAPWS R10-06, 2009)

$\mu_{\mathrm{W}}^{\mathrm{Ih}}=g^{\mathrm{Ih}}$.

Chemical potentials per mole of water, $\mu$, may similarly be expressed by so-called fugacities, $f$ (symbol not to be confused here with the Helmholtz functions, $f$, considered earlier), according to the relation (Guggenheim, 1949; Prausnitz et al., 1999)

$\mu=\mu^{\mathrm{id}}+R T \ln \frac{f}{x p}$.

Here, $x$ is the mole fraction of water in the substance considered, $\mu^{\text {id }}$ is the ideal-gas chemical potential of water vapour with the same number of moles and $R$ is the molar gas constant. It is obvious from Eq. (19) that the fugacity, $f$, plays the role for a real gas which the partial pressure, $x p$, plays for an ideal gas (Lewis, 1901). Regardless of the wind conditions, evaporation from the ocean ceases when the fugacity of water in seawater equals the fugacity of water in humid air. This fact makes hot humid tropics so unpleasant to humans because sweating provides no cooling there. A statement similar to that for the fugacities may not be made for partial pressures, however, as a fictitious "partial pressure of water in seawater" is not a well-defined quantity, and the partial pressure of water in humid air does not state any thermodynamic criterion for phase equilibria. For these physical reasons, TEOS-10 suggests a replacement of the usual definition of relative humidity in terms of partial pressures by a new definition in terms of fugacities (IOC et al., 2010, Sect. 3.40 therein; Feistel et al., 2010b, 2015, 2016; Feistel, 2012; IAPWS G11-15, 2015; Feistel and Lovell-Smith, 2017). In fact, the small real-gas effects of the atmosphere are of similar magnitude as the expected changes in relative humidity associated with greenhouse effects (Hellmuth et al., 2018).

\section{Summary}

TEOS-10 is the present international standard for the thermodynamic properties of water, ice, seawater and humid air recommended for geosciences by leading international organisations such as UNESCO/IOC and IUGG. TEOS-10 incorporates an extended manifold of different experimental data 
for those substances, collected from publications over many decades, in an unprecedentedly compact, consistent, comprehensive and accurate way based on an axiomatic approach that offers various advantages over otherwise relatively arbitrary collections of empirical property equations with often unclear mutual consistency. However, certain important problems remain to be addressed even after the introduction of TEOS-10. In particular, the climatological key parameters ocean salinity, seawater $\mathrm{pH}$ and atmospheric relative humidity still pose metrological challenges that are currently investigated by the standing SCOR/IAPSO/IAPWS Joint Committee on the Properties of Seawater, JCS, in cooperation with other international organisations.
Data availability. TEOS-10 equations are freely available from the internet at http://www.teos-10.org and http://www.iapws.org (last access: 8 June 2018), as well as from the article "Thermodynamic properties of sea air", https://doi.org/10.5194/os-6-91-2010, in the Ocean Science Special Issue 14 "Thermophysical properties of seawater". 


\section{Appendix A: The Jacobi method}

Consider $N$ functions, $y_{1}, y_{2}, \ldots y_{N}$, depending on $N$ independent variables, $x_{1}, x_{2}, \ldots x_{N}$. The matrix $\mathbf{A}=\left\{a_{i j}\right\}$ consisting of their pairwise partial derivatives, $a_{i j}=\partial y_{i} / \partial x_{j}$, as its elements is regarded as the Jacobian matrix of this set of functions. The determinant $J=|\mathbf{A}|=\operatorname{det}\left\{a_{i j}\right\}$ of this matrix is commonly referred to as the functional determinant or the Jacobian (Bronstein and Semendjajew, 1979; Kaplan, 1984; Gradshteyn and Ryshik, 2000). It is instructive to write $J$ in the form of a fraction:

$J=\operatorname{det}\left\{\frac{\partial y_{i}}{\partial x_{j}}\right\}=\frac{\partial\left(y_{1}, y_{2}, \ldots y_{N}\right)}{\partial\left(x_{1}, x_{2}, \ldots x_{N}\right)}$.

For $N=1$, the Jacobian agrees with the partial derivative:

$J=\frac{\partial\left(y_{1}\right)}{\partial\left(x_{1}\right)}=\frac{\partial y_{1}}{\partial x_{1}}$.

Determinants of higher dimensions $N$ can be computed by means of the so-called Laplace expansion with respect to a selected row or column of the matrix and the related remaining submatrices, the minors of dimension $N-1$. For $N=2$, the Jacobian reads

$$
\begin{aligned}
J=\frac{\partial\left(y_{1}, y_{2}\right)}{\partial\left(x_{1}, x_{2}\right)}= & \frac{\partial y_{1}}{\partial x_{1}} \times \frac{\partial\left(y_{2}\right)}{\partial\left(x_{2}\right)}-\frac{\partial y_{1}}{\partial x_{2}} \times \frac{\partial\left(y_{2}\right)}{\partial\left(x_{1}\right)} \\
& =\frac{\partial y_{1}}{\partial x_{1}} \frac{\partial y_{2}}{\partial x_{2}}-\frac{\partial y_{1}}{\partial x_{2}} \frac{\partial y_{2}}{\partial x_{1}}
\end{aligned}
$$

where the two-dimensional Jacobian is expressed in terms of one-dimensional Jacobians.

For $N=3$, the Laplace expansion takes the form

$$
\begin{aligned}
J= & \frac{\partial\left(y_{1}, y_{2}, y_{3}\right)}{\partial\left(x_{1}, x_{2}, x_{3}\right)}=\frac{\partial y_{1}}{\partial x_{1}} \times \frac{\partial\left(y_{2}, y_{3}\right)}{\partial\left(x_{2}, x_{3}\right)}-\frac{\partial y_{1}}{\partial x_{2}} \\
& \times \frac{\partial\left(y_{2}, y_{3}\right)}{\partial\left(x_{1}, x_{3}\right)}+\frac{\partial y_{1}}{\partial x_{3}} \times \frac{\partial\left(y_{2}, y_{3}\right)}{\partial\left(x_{1}, x_{2}\right)},
\end{aligned}
$$

where the three-dimensional Jacobian is expanded into products of one- and two-dimensional Jacobians. Equations (A3) and (A4) are the most frequently used relations required for deriving TEOS-10 functions with two or three independent variables.

Here are some useful manipulation rules for Jacobians. The general properties of determinants imply that the exchange of any two variables switches the sign of the Jaco- bian, e.g.

$$
\begin{aligned}
\frac{\partial\left(y_{1}, \ldots, y_{i}, \ldots, y_{j}, \ldots y_{N}\right)}{\partial\left(x_{1}, x_{2}, \ldots x_{N}\right)} \\
=-\frac{\partial\left(y_{1}, \ldots, y_{j}, \ldots, y_{i}, \ldots y_{N}\right)}{\partial\left(x_{1}, x_{2}, \ldots x_{N}\right)},
\end{aligned}
$$

and similarly,

$$
\begin{aligned}
& \frac{\partial\left(y_{1}, \ldots y_{N}\right)}{\partial\left(x_{1}, \ldots x_{i}, \ldots x_{j}, \ldots x_{N}\right)} \\
& =-\frac{\partial\left(y_{1}, \ldots y_{N}\right)}{\partial\left(x_{1}, \ldots x_{j}, \ldots x_{i}, \ldots x_{N}\right)} .
\end{aligned}
$$

For $N=2$, this means

$$
\begin{aligned}
& \frac{\partial\left(y_{1}, y_{2}\right)}{\partial\left(x_{1}, x_{2}\right)}=-\frac{\partial\left(y_{2}, y_{1}\right)}{\partial\left(x_{1}, x_{2}\right)}=-\frac{\partial\left(y_{1}, y_{2}\right)}{\partial\left(x_{2}, x_{1}\right)} \\
& \quad=\frac{\partial\left(y_{2}, y_{1}\right)}{\partial\left(x_{2}, x_{1}\right)} .
\end{aligned}
$$

As special cases for $N=3$, the reversal of variables inverts the sign,

$$
\begin{aligned}
& \frac{\partial\left(y_{1}, y_{2}, y_{3}\right)}{\partial\left(x_{1}, x_{2}, x_{3}\right)}=-\frac{\partial\left(y_{3}, y_{2}, y_{1}\right)}{\partial\left(x_{1}, x_{2}, x_{3}\right)}=-\frac{\partial\left(y_{1}, y_{2}, y_{3}\right)}{\partial\left(x_{3}, x_{2}, x_{1}\right)} \\
& \quad=\frac{\partial\left(y_{3}, y_{2}, y_{1}\right)}{\partial\left(x_{3}, x_{2}, x_{1}\right)},
\end{aligned}
$$

while the rotation of variables preserves the sign,

$$
\begin{gathered}
\frac{\partial\left(y_{1}, y_{2}, y_{3}\right)}{\partial\left(x_{1}, x_{2}, x_{3}\right)}=\frac{\partial\left(y_{3}, y_{1}, y_{2}\right)}{\partial\left(x_{1}, x_{2}, x_{3}\right)}=\frac{\partial\left(y_{2}, y_{3}, y_{1}\right)}{\partial\left(x_{1}, x_{2}, x_{3}\right)} \\
=\frac{\partial\left(y_{1}, y_{2}, y_{3}\right)}{\partial\left(x_{3}, x_{1}, x_{2}\right)}=\frac{\partial\left(y_{1}, y_{2}, y_{3}\right)}{\partial\left(x_{2}, x_{3}, x_{1}\right)} .
\end{gathered}
$$

If one (or more) of the functions is an identity, say, $y_{N}\left(x_{1}, \ldots x_{N}\right) \equiv x_{N}$, the Jacobian reduces by one dimension (or more) due to the Laplace expansion:

$$
\frac{\partial\left(y_{1}, y_{2}, \ldots y_{N-1}, x_{N}\right)}{\partial\left(x_{1}, x_{2}, \ldots x_{N-1}, x_{N}\right)}=\frac{\partial\left(y_{1}, y_{2}, \ldots y_{N-1}\right)}{\partial\left(x_{1}, x_{2}, \ldots x_{N-1}\right)} .
$$

In particular, the identical Jacobian equals unity:

$\frac{\partial\left(x_{1}, x_{2}, \ldots x_{N-1}, x_{N}\right)}{\partial\left(x_{1}, x_{2}, \ldots x_{N-1}, x_{N}\right)}=1$.

The product rule for functional determinants of higher dimensions is a generalisation of the usual chain rule for partial derivatives. If a set of functions $\boldsymbol{z}$ depends on the variables $\boldsymbol{y}$, which in turn depend on the variables $\boldsymbol{x}$, the relation between their Jacobians is (Bronstein and Semenjajew, 1979)

$$
\begin{aligned}
\frac{\partial\left(z_{1}, z_{2}, \ldots z_{N}\right)}{\partial\left(x_{1}, x_{2}, \ldots x_{N}\right)}= & \frac{\partial\left(z_{1}, z_{2}, \ldots z_{N}\right)}{\partial\left(y_{1}, y_{2}, \ldots y_{N}\right)} \\
& \times \frac{\partial\left(y_{1}, y_{2}, \ldots y_{N}\right)}{\partial\left(x_{1}, x_{2}, \ldots x_{N}\right)} .
\end{aligned}
$$

In particular, if the functions $z$ are chosen identical to $\boldsymbol{x}$, for the inverse functions there follows from Eq. (A12)

$$
\frac{\partial\left(y_{1}, y_{2}, \ldots y_{N}\right)}{\partial\left(x_{1}, x_{2}, \ldots x_{N}\right)}=\left[\frac{\partial\left(x_{1}, x_{2}, \ldots x_{N}\right)}{\partial\left(y_{1}, y_{2}, \ldots y_{N}\right)}\right]^{-1} \text {. }
$$


Developed by Shaw (1935), the Jacobi method is the mathematically most elegant way of transforming the various partial derivatives of different thermodynamic potentials into one another, exploiting the convenient formal calculus of functional determinants (Margenau and Murphy, 1943; Landau and Lifschitz, 1966). Namely, if any thermodynamic derivative in two variables, $(\partial u / \partial x)_{y}$, is considered, it can formally be written as a Jacobian (Eq. A10):

$$
\left(\frac{\partial u}{\partial x}\right)_{y} \equiv \frac{\partial(u, y)}{\partial(x, y)}
$$

If this Jacobian is to be expressed in specific variables, say $T$ and $p$, the transformation into these independent variables follows from Eq. (A12) as

$$
\left(\frac{\partial u}{\partial x}\right)_{y}=\frac{\frac{\partial(u, y)}{\partial(T, p)}}{\frac{\partial(x, y)}{\partial(T, p)}} .
$$

If any of the variables $u, x, y$ equal $T$ or $p$, the numerator or denominator of Eq. (A15) can be simplified by means of the rules (A7) and (A10). If not, we get the result for Eq. (A15) from Eq. (A3):

$$
\left(\frac{\partial u}{\partial x}\right)_{y}=\frac{\frac{\partial(u, y)}{\partial(T, p)}}{\frac{\partial(x, y)}{\partial(T, p)}}=\frac{\left(\frac{\partial u}{\partial T}\right)_{p}\left(\frac{\partial y}{\partial p}\right)_{T}-\left(\frac{\partial y}{\partial T}\right)_{p}\left(\frac{\partial u}{\partial p}\right)_{T}}{\left(\frac{\partial x}{\partial T}\right)_{p}\left(\frac{\partial y}{\partial p}\right)_{T}-\left(\frac{\partial y}{\partial T}\right)_{p}\left(\frac{\partial x}{\partial p}\right)_{T}} .
$$

As an example, we compute the sound speed, $c$ (Eq. 7), in terms of derivatives of the Gibbs function $g(T, p)$ and of the Helmholtz function, $f(T, \rho)$. For the Gibbs function we get from Eq. (A16)

$$
\begin{aligned}
c^{2}= & \left(\frac{\partial p}{\partial \rho}\right)_{\eta}=\frac{\partial(p, \eta)}{\partial(\rho, \eta)}=\frac{\frac{\partial(p, \eta)}{\partial(T, p)}}{\frac{\partial(\rho, \eta)}{\partial(T, p)}} \\
= & \frac{-\left(\frac{\partial \eta}{\partial T}\right)_{p}}{\left(\frac{\partial \rho}{\partial T}\right)_{p}\left(\frac{\partial \eta}{\partial p}\right)_{T}-\left(\frac{\partial \eta}{\partial T}\right)_{p}\left(\frac{\partial \rho}{\partial p}\right)_{T}} .
\end{aligned}
$$

Substituting in Eq. (A17) the variables $\rho$ and $\eta$, respectively, by means of $g_{p}=v=1 / \varrho$ and $g_{T}=-\eta$, where partial derivatives of $g$ are now conveniently written as subscripts, the final formula for the sound speed expressed in terms of the Gibbs function reads

$c=g_{p} \sqrt{\frac{g_{T T}}{g_{T p}^{2}-g_{T T} g_{p p}}}$.

Alternatively, for the Helmholtz function we get from Eq. (A16) the sound speed formula, replacing in Eq. (A17) the independent variable $p$ by $\rho$ :

$$
\begin{aligned}
c^{2}= & \left(\frac{\partial p}{\partial \rho}\right)_{\eta}=\frac{\partial(p, \eta)}{\partial(\rho, \eta)}=\frac{\frac{\partial(p, \eta)}{\partial(T, \rho)}}{\frac{\partial(\rho, \eta)}{\partial(T, \rho)}} \\
= & \frac{\left(\frac{\partial p}{\partial T}\right)_{\rho}\left(\frac{\partial \eta}{\partial \rho}\right)_{T}-\left(\frac{\partial \eta}{\partial T}\right)_{\rho}\left(\frac{\partial p}{\partial \rho}\right)_{T}}{-\left(\frac{\partial \eta}{\partial T}\right)_{\rho}} .
\end{aligned}
$$

Substituting in Eq. (A19) the variables $p$ and $\eta$, respectively, by means of $\varrho^{2} f_{\varrho}=p$ and $f_{T}=-\eta$, the final formula for the sound speed expressed in terms of the Helmholtz function reads

$c=\sqrt{\frac{-\varrho^{2} f_{T \varrho}^{2}}{f_{T T}}+2 \varrho f_{\varrho}+\varrho^{2} f_{\varrho \varrho}}$.

For more independent variables, such as the additional mass fractions of sea salt or dry air, the method applies correspondingly. If a derivative $(\partial u / \partial x)_{y, z}$ is to be calculated, we apply the rule (A10):

$$
\left(\frac{\partial u}{\partial x}\right)_{y, z} \equiv \frac{\partial(u, y, z)}{\partial(x, y, z)} .
$$

If this derivative of an arbitrary function $u(x, y, z)$ needs to be expressed in, say, the particular variables $S, T, p$ of the Gibbs function of seawater, Eq. (A21) needs to be transformed to those variables by the thermodynamic "chain rule":

$$
\left(\frac{\partial u}{\partial x}\right)_{y, z} \equiv \frac{\partial(u, y, z)}{\partial(x, y, z)}=\frac{\partial(u, y, z)}{\partial(S, T, p)} / \frac{\partial(x, y, z)}{\partial(S, T, p)} .
$$

Then, the Jacobians in the numerator and denominator are evaluated by the rules (A4), (A8), (A9) and (A10) until (A22) is eventually expressed by the Gibbs function $g$ and its derivatives with respect to $S, T$ and $p$.

\section{Appendix B: Meetings of SCOR/IAPSO WG127}

WG127 was formed as a small group of specialists from countries all over the world. After the WG was established in 2005, the WG Chair, Trevor McDougall, was its first, natural member who decided to invite Rainer Feistel as a second member. Possible further candidates were then commonly discussed and contacted as the next potential member. So the democratic invitation process went on up to the intended maximum size of the group. Rather than face to face, many of the members knew each other only from publications. Despite this, the work of WG127 was very constructive and intense from the first day on. Year by year, the membership varied slightly, bringing new expertise into the discussions and decisions. Until the adoption of TEOS-10 in 2009, the participants of the four WG127 meetings may briefly be 


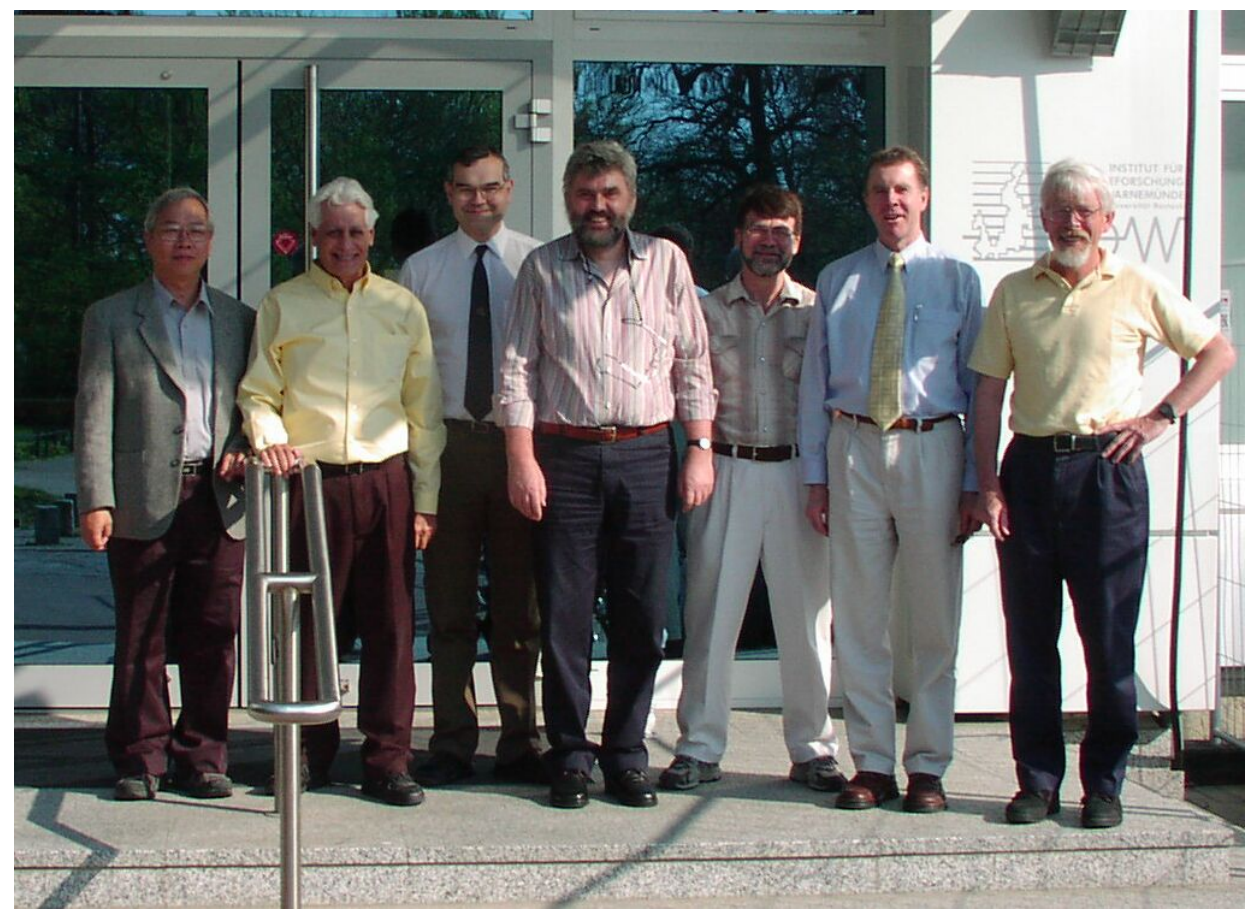

Figure B1. Participants from left to right: Chen-Tung Arthur Chen (Taiwan), Frank J. Millero (USA), Brian A. King (UK), Rainer Feistel (Germany), Daniel G. Wright (Canada), Trevor J. McDougall (Australia), Giles M. Marion (USA). Photo taken in front of the Baltic Sea Research Institute, IOW.

reported here with appreciation and gratitude for their substantial contributions and very successful cooperation during those years. It was very sad, however, that two extremely productive and creative friends and colleagues were lost quite untimely: Dan Wright died in 2010, and David Jackett in 2012. In memory, TEOS-10 will always be associated with their names.

- 2006 initial meeting at Warnemünde, Germany, 2 to 5 May; see Fig. B1

- 2007 meeting at Reggio, Calabria, Italy, 7 to 10 May; see Fig. B2

- 2008 meeting at Goetz near Berlin, Germany, 3 to 9 September; see Fig. B3

- 2009 final meeting at Arnhem, the Netherlands, 2 to 5 September

Participants (alphabetically, no photo available): Rainer Feistel (Germany), Brian A. King (UK), Norge Larson (USA), Trevor J. McDougall (Australia), Richard Pawlowicz (Canada), Daniel G. Wright (Canada). 


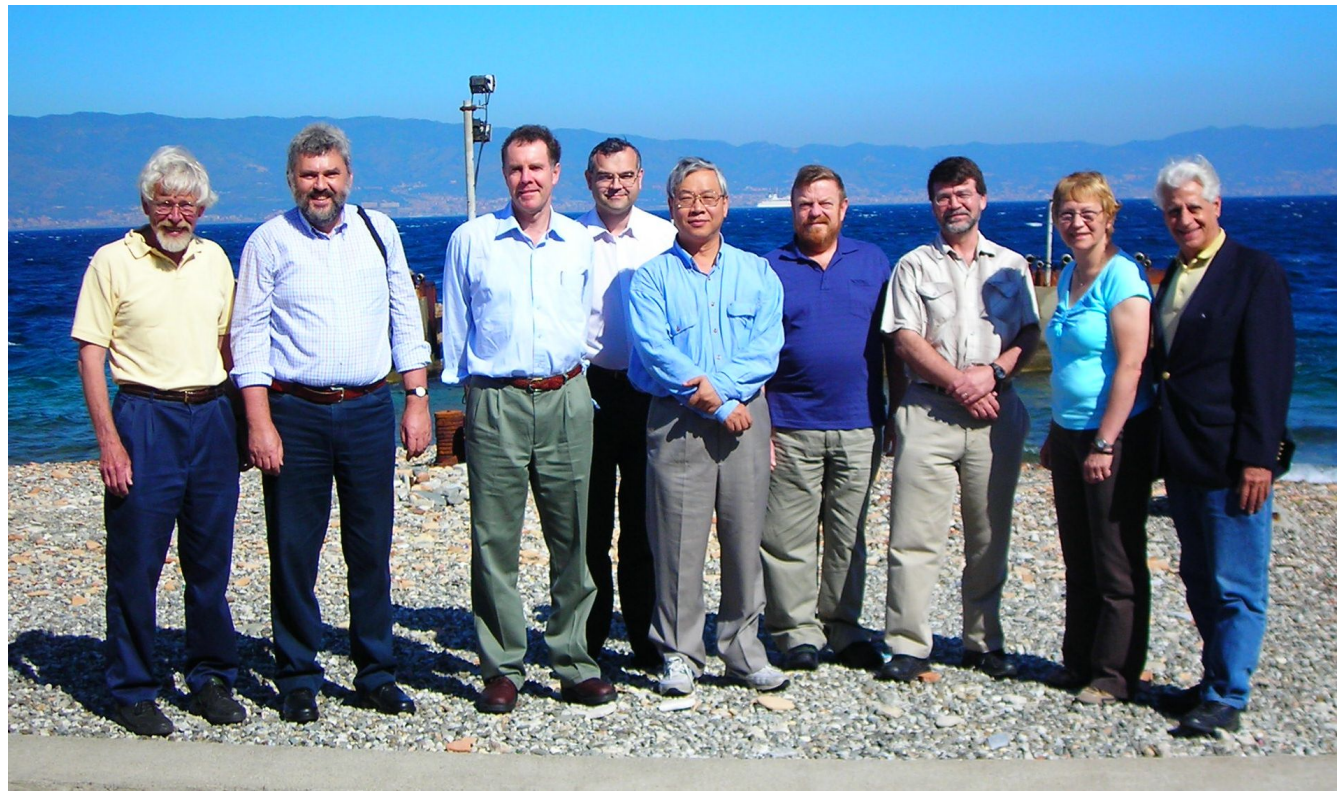

Figure B2. Participants from left to right: Giles M. Marion (USA), Rainer Feistel (Germany), Trevor J. McDougall (Australia), Brian A. King (UK), Chen-Tung Arthur Chen (Taiwan), David Jackett (Australia), Daniel G. Wright (Canada), Petra Spitzer (Germany), Frank J. Millero (USA). Photo taken at the shore of the Strait of Messina, with the island of Sicily in the background.

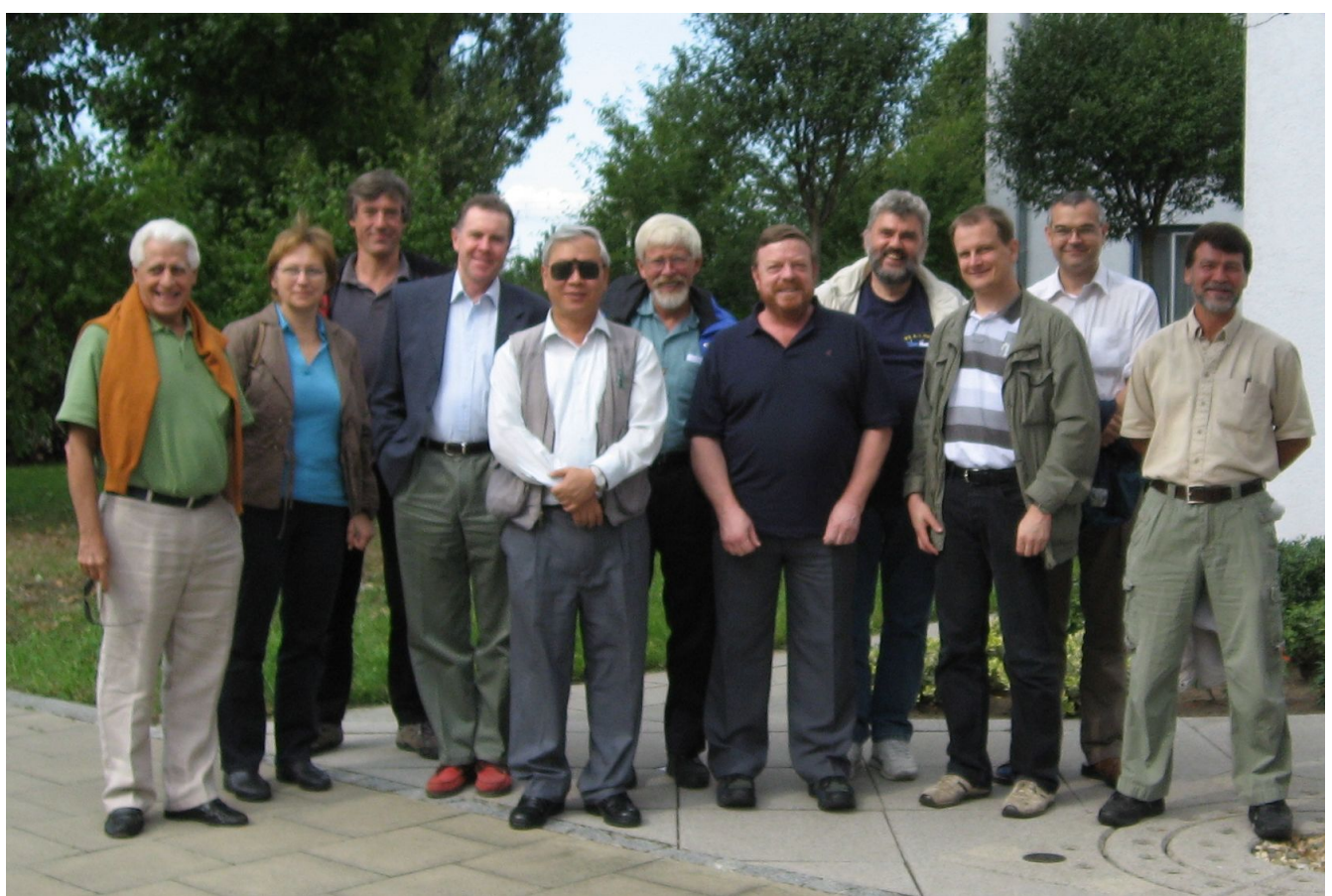

Figure B3. Participants from left to right: Frank J. Millero (USA), Petra Spitzer (Germany), Nigel Higgs (UK), Trevor J. McDougall (Australia), Chen-Tung Arthur Chen (Taiwan), Giles M. Marion (USA), David Jackett (Australia), Rainer Feistel (Germany), Steffen Seitz (Germany), Brian A. King (UK), Daniel G. Wright (Canada). 
Competing interests. The author declares no conflict of interest.

Acknowledgements. This review article was written on the occasion of receiving the 2018 Fridtjof Nansen Medal of the European Geosciences Union. The author thanks the reviewers, Trevor McDougall and Remi Tailleux, as well as the OS topic editor, Mario Hoppema, for their helpful suggestions.

Edited by: Mario Hoppema

Reviewed by: Trevor McDougall and Remi Tailleux

\section{References}

Abbot, C. G. and Fowle Jr., F. E.: Income and Outgo of Heat from the Earth, and the Dependence of Its Temperature Thereon, Annals of the Astrophysical Observatory (Smithsonian Institution, Washington DC), 2, 159-176, 1908.

Alberty, R. A.: Use of Legendre transforms in chemical thermodynamics, Pure Appl. Chem., 73, 1349-1380, https://doi.org/10.1351/pac200173081349, 2001.

Arrhenius, S.: On the Influence of Carbonic Acid in the Air upon the Temperature of the Ground, London, Edinburgh, and Dublin, Philosophical Magazine and Journal of Science (fifth series), 41, 237-275, 1896.

Bielska, K., Havey, D. K., Scace, G. E., Lisak, D., Harvey, A. H., and Hodges, J. T.: High-accuracy measurements of the vapor pressure of ice referenced to the triple point, Geophys. Res. Lett., 40, 6303-6307, https://doi.org/10.1002/2013GL058474, 2013.

Bigg, P. H.: Density of water in S.I. units over the range 0-40 C, Brit. J. Appl. Phys., 18, 521-537, 1967.

Bjerrum, N.: On the activity-coefficient for ions, Meddelanden från Kungliga Vetenskapsakademiens Nobelinstitut, 5, 1-21, German translation: Der Aktivitätskoeffizient der lonen, Zeitschrift für anorganische und allgemeine Chemie, 109, 275-292, 1920, https://doi.org/10.1002/zaac.19201090119, 1919.

Bjerrum, N.: Ionic association. I. Influence of ionic association on the activity of ion at moderate degree of association, Det Kongelige Danske videnskabernes selskabs skrifter 7, 1-48, 1926.

Brewer, P. G.: A short history of ocean acidification science in the 20th century: a chemist's view, Biogeosciences, 10, 7411-7422, https://doi.org/10.5194/bg-10-7411-2013, 2013.

Bronstein, I. N. and Semendjajew, K. A.: Taschenbuch der Mathematik, Nauka, Moscow, and Teubner, Leipzig, 1979.

Budéus, G. Th.: Potential bias in TEOS10 density of sea water samples, Deep-Sea Res. Pt. I, 134, 41-47, https://doi.org/10.1016/j.dsr.2018.02.005, 2018.

Burchard, H., Bolding, K., Feistel, R., Gräwe, U., Klingbeil, K., MacCready, P., Mohrholz, V., Umlauf, L., and van der Lee, E. M.: The Knudsen theorem and the Total Exchange Flow analysis framework applied to the Baltic Sea, Prog. Oceanogr., https://doi.org/10.1016/j.pocean.2018.04.004, in press, 2018.

Caldwell, D. R.: The maximum density points of pure and saline water, Deep-Sea Res., 25, 175-181, https://doi.org/10.1016/0146-6291(78)90005-X, 1978.

Camões, F., Anes, B., Martins, H., Oliveira, C., Fisicaro, P., Stoica, D., and Spitzer, P.: Assessment of $\mathrm{H}^{+}$in complex aqueous solu- tions approaching seawater, J. Electroanal. Chem., 764, 88-92, https://doi.org/10.1016/j.jelechem.2016.01.014, 2016.

Carritt, D. E.: Chemical instrumentation, The Sea, Volume 2, The Composition of Sea-Water, Comparative and Descriptive Oceanography, edited by: Hill, M. N., Wiley, New York, 109123, 1963.

CCT: Recommendation $\mathrm{T} 1$ for a new definition of the kelvin in 2018, Consultative Committee for Thermometry (CCT), Report of the 28th meeting (1-2 June 2017) to the International Committee for Weights and Measures, Bureau International des Poids et Mesures, Sèvres, available at: https://www.bipm. org/utils/common/pdf/CC/CCT/CCT28.pdf (last access: 9 June 2018), 2017.

Chen, C. T. and Millero, F. J.: Sound speed of seawater at high pressures, J. Acoust. Soc. Am., 62, 1129-1135, https://doi.org/10.1121/1.381646, 1977.

Chen, C. T. and Millero, F. J.: Precise thermodynamical properties for natural waters covering only the limnological range, Limnol. Oceanogr., 31, 657-662, https://doi.org/10.4319/lo.1986.31.3.0657, 1986.

Cheng, L., Trenberth, K. E., Palmer, M. D., Zhu, J., and Abraham, J. P.: Observed and simulated full-depth ocean heatcontent changes for 1970-2005, Ocean Sci., 12, 925-935, https://doi.org/10.5194/os-12-925-2016, 2016.

CGPM: On the revision of the International System of Units (SI). Draft Resolution A - 26th meeting of the CGPM (13-16 November 2018), The General Conference on Weights and Measures (CGPM), available at: https://www.bipm.org/utils/en/pdf/ CGPM/Draft-Resolution-A-EN.pdf (last access: 9 June 2018), 2018.

Culkin, F. and Smed, J.: History of standard seawater, Oceanol. Acta, 2, 355-364, available at: http://archimer.ifremer.fr/doc/ 00122/23351/, (last access: 9 June 2018), 1979.

De Bievre, P. and Günzler, H. (Eds.): Traceability in Chemical Measurement, Springer-Verlag, Berlin, Heidelberg, 2005.

De Groot, S. R. and Mazur, P.: Non-equilibrium Thermodynamics, Dover Publications, New York, 1984.

Del Grosso, V. A.: New equation for the speed of sound in natural waters (with comparison to other equations), J. Acoust. Soc. Am., 56, 1084-1091, https://doi.org/10.1121/1.1903388, 1974.

Dickson, A. G.: pH scales and proton-transfer reactions in saline media such as sea water, Geochim. Cosmochim. Ac., 48, 2299 2308, https://doi.org/10.1016/0016-7037(84)90225-4, 1984.

Dickson, A. G., Camões, M. F., Spitzer, P., Fisicaro, P., Stoica, D., Pawlowicz, R., and Feistel, R.: Metrological challenges for measurements of key climatological observables. Part 3: Seawater pH, Metrologia, 53, R26-R39, https://doi.org/10.1088/00261394/53/1/R26, 2016.

Dorsey, N. E.: Properties of Ordinary Water-Substance, Hafner Publishing Company, New York, 1968.

Dushaw, B. D., Worcester, P. F., Cornuelle, B. D., and Howe, B. M.: On equations for the speed of sound in seawater, J. Acoust. Soc. Am., 94, 255-275, https://doi.org/10.1121/1.405660, 1993.

Ebeling, W. and Grigo, M.: Mean spherical approximationmass action law theory of equilibrium and conductance in ionic solutions, J. Solution Chem., 11, 151-167, https://doi.org/10.1007/BF00667599, 1982. 
Ebeling, W. and Scherwinski, K.: On the estimation of theoretical individual activity coefficients of electrolyte, Z. Phys. Chem., Leipzig, 264, 1-14, 1983.

Emden, R.: Über Strahlungsgleichgewicht und atmosphärische Strahlung, Ein Beitrag zur Theorie der oberen Inversion, Sitzungsberichte der mathematisch-physikalischen Klasse der Königlich Bayerischen Akademie der Wissenschaften zu München, Jahrgang 1913, 55-142, 1913.

Emery, W. J., Talley, L. D., and Pickard, G. L.: Descriptive Physical Oceanography, Elsevier, Amsterdam, 2006.

Falkenhagen, H., Ebeling, W., and Hertz, H. G.: Theorie der Elektrolyte, S. Hirzel Verlag, Leipzig, 1971.

Fasullo, J. T. and Trenberth, K. E.: A Less Cloudy Future: The Role of Subtropical Subsidence in Climate Sensitivity, Science, 338, 792-794, https://doi.org/10.1126/science.1227465, 2012.

Feely, R. A., Sabine, C. L., Lee, K., Berelson, W., Kleypas, J., Fabry, V. J., and Millero, F. J.: Impact of Anthropogenic $\mathrm{CO}_{2}$ on the $\mathrm{CaCO}_{3}$ System in the Oceans, Science, 305, 362-366, https://doi.org/10.1126/science.1097329, 2004.

Feistel, R.: Thermodynamics of Seawater, in: German Democratic Republic National Report for the period 1.1.19872.10.1990 (Final Report), edited by: Striggow, K. and Schröder, A., IAPSO, presented at the XX. General Assembly of the IUGG, Wien 1991, Institut für Meereskunde, Warnemünde, https://doi.org/10.13140/RG.2.1.3973.3282, 1991.

Feistel, R.: Equilibrium thermodynamics of seawater revisited, Prog. Oceanogr., 31, 101-179, https://doi.org/10.1016/00796611(93)90024-8, 1993.

Feistel, R.: A new extended Gibbs thermodynamic potential of seawater, Prog. Oceanogr., 58, 43-114, https://doi.org/10.1016/S0079-6611(03)00088-0, 2003.

Feistel, R.: A Gibbs function for seawater thermodynamics for -6 to $80^{\circ} \mathrm{C}$ and salinity up to $120 \mathrm{~g} \mathrm{~kg}^{-1}$, Deep-Sea Res. Pt. I, 55, 1639-1671, https://doi.org/10.1016/j.dsr.2008.07.004, 2008.

Feistel, R.: Extended equation of state for seawater at elevated temperature and salinity, Desalination, 250, 14-18, https://doi.org/10.1016/j.desal.2009.03.020, 2010.

Feistel, R.: TEOS-10: A New International Oceanographic Standard for Seawater, Ice, Fluid Water, and Humid Air, Int. J. Thermophys., 33, 1335-1351, https://doi.org/10.1007/s10765-0100901-y, 2012.

Feistel, R.: Water, Steam and Climate, Proc. 16th Int. Conf. on the Properties of Water and Steam (Greenwich, UK, 1-5 September 2013), https://doi.org/10.13140/2.1.3855.9043, 2013.

Feistel, R.: Salinity and relative humidity: climatological relevance and metrological needs, Acta IMEKO, 4, 57-61, https://doi.org/10.21014/acta_imeko.v4i4.216, 2015.

Feistel, R.: Salzgehalt des Meeres und relative Feuchte der Luft: Rolle im Klimasystem und Probleme ihrer Definition [Salinity of the sea and relative humidity of the air: role in the climate system and problems of their definition], Leibniz Online, 25, 120, available at: https://leibnizsozietaet.de/wp-content/uploads/ 2017/01/Feistel.pdf (last access: 9 June 2018), 2017.

Feistel, R. and Ebeling, W.: Physics of Self-Organization and Evolution, Wiley-VCH, Weinheim, 2011.

Feistel, R. and Feistel, S.: Die Ostsee als thermodynamisches System [The Baltic Sea as a thermodynamic system], in: Irreversible Prozesse und Selbstorganisation, edited by: Schimansky-Geier, L., Malchow, H. and Pöschel, T., Logos-Verlag, Berlin, 247-
264, available at: http://www.mss.cbi.fau.de/content/uploads/ EbBook.pdf (last access: 9 June 2018), 2006.

Feistel, R. and Hagen, E.: Thermodynamic Quantities in Oceanography, in: The Oceans: Physical-Chemical Dynamics and Human Impact, edited by: Majumdar, S. K., Miller, G. S., Schmalz, R. F., and Panah, A. A., The Pennsylvania Academy of Science, Easton, PA, 1-16, https://doi.org/10.1016/0079-6611(96)000018, 1994

Feistel, R. and Hagen, E.: On the GIBBS thermodynamic potential of seawater, Prog. Oceanogr., 36, 249-327, https://doi.org/10.1016/S0165-232X(98)00014-7, 1995.

Feistel, R. and Hagen, E.: A Gibbs thermodynamic potential of sea ice, Cold Reg. Sci. Technol., 28, 83-142, https://doi.org/10.1088/1681-7575/aa7083, 1998.

Feistel, R. and Lovell-Smith, J. W.: Defining relative humidity in terms of water activity. Part 1: definition, Metrologia, 54, 566576, https://doi.org/10.1016/j.pocean.2007.04.020, 2017.

Feistel, R. and Marion, G. M.: A Gibbs-Pitzer function for highsalinity seawater thermodynamics, Prog. Oceanogr., 74, 515539, 2007.

Feistel, R. and Wagner, W.: A Comprehensive Gibbs Thermodynamic Potential of Ice, Proceedings of the 14th International Conference on the Properties of Water and Steam, Kyoto, Japan, 30 August-3 September 2004, 10.13140/2.1.1619.4880, 2004.

Feistel, R. and Wagner, W.: High-pressure thermodynamic Gibbs functions of ice and sea ice, J. Mar. Res., 63, 95-139, https://doi.org/10.1357/0022240053693789, 2005.

Feistel, R. and Wagner, W.: A new equation of state for $\mathrm{H}_{2} \mathrm{O}$ ice Ih, J. Phys. Chem. Ref. Data, 35, 1021-1047, https://doi.org/10.1063/1.2183324, 2006.

Feistel, R. and Wagner, W.: Sublimation pressure and sublimation enthalpy of $\mathrm{H}_{2} \mathrm{O}$ ice Ih between 0 and $273.16 \mathrm{~K}$, Geochim. Cosmochim. Ac., 71, 36-45, https://doi.org/10.1063/1.3657937, 2007.

Feistel, R., Lovell-Smith, J., and Hellmuth, O.: Virial Approximation of the TEOS-10 Equation for the Fugacity of Water in Humid Air, Int. J. Thermophys., 36, 44-68, https://doi.org/10.1007/s10765-014-1784-0, 2015.

Feistel, R., Wright, D. G., Miyagawa, K., Harvey, A. H., Hruby, J., Jackett, D. R., McDougall, T. J., and Wagner, W.: Mutually consistent thermodynamic potentials for fluid water, ice and seawater: a new standard for oceanography, Ocean Sci., 4, 275-291, https://doi.org/10.5194/os-4-275-2008, 2008a.

Feistel, R., Tailleux, R., and McDougall, T.: Thermophysical properties of seawater, Ocean Sci., https://www.ocean-sci.net/ special_issue14.html (last access: 9 June 2018), 2008b.

Feistel, R., Wright, D. G., Jackett, D. R., Miyagawa, K., Reissmann, J. H., Wagner, W., Overhoff, U., Guder, C., Feistel, A., and Marion, G. M.: Numerical implementation and oceanographic application of the thermodynamic potentials of liquid water, water vapour, ice, seawater and humid air - Part 1: Background and equations, Ocean Sci., 6, 633-677, https://doi.org/10.5194/os-6633-2010, 2010a.

Feistel, R., Wright, D. G., Kretzschmar, H.-J., Hagen, E., Herrmann, S., and Span, R.: Thermodynamic properties of sea air, Ocean Sci., 6, 91-141, https://doi.org/10.5194/os-6-91-2010, 2010b.

Feistel, R., Weinreben, S., Wolf, H., Seitz, S., Spitzer, P., Adel, B., Nausch, G., Schneider, B., and Wright, D. G.: Density and Ab- 
solute Salinity of the Baltic Sea 2006-2009, Ocean Sci., 6, 3-24, https://doi.org/10.5194/os-6-3-2010, 2010c.

Feistel, R., Marion, G. M., Pawlowicz, R., and Wright, D. G.: Thermophysical property anomalies of Baltic seawater, Ocean Sci., 6, 949-981, https://doi.org/10.5194/os-6-949-2010, $2010 \mathrm{~d}$.

Feistel, R., Wielgosz, R., Bell, S. A., Camões, M. F., Cooper, J. R., Dexter, P., Dickson, A. G., Fisicaro, P., Harvey, A. H., Heinonen, M., Hellmuth, O., Kretzschmar, H.-J., Lovell-Smith, J. W., McDougall, T. J., Pawlowicz, R., Ridout, R., Seitz, S., Spitzer, P., Stoica, D., and Wolf, H.: Metrological challenges for measurements of key climatological observables: Oceanic salinity and $\mathrm{pH}$, and atmospheric humidity. Part 1: overview, Metrologia, 53, R1-R11, https://doi.org/10.1088/0026-1394/53/1/R1, 2016.

Fellmuth, B., Fischer, J., Machin, G., Picard, S., Steur, P. P. M., Tamura, O., White, D. R., and Yoon, H.: The kelvin redefinition and its mise en pratique, Philos. T. R. Soc. A, 374, 20150037, https://doi.org/10.1098/rsta.2015.0037, 2016.

Fernicola, V., Rosso, L., and Giovannini, M.: Investigation of the Ice-Water Vapor Equilibrium Along the Sublimation Line, Int. J. Thermophys., 33, 1363-1373, https://doi.org/10.1007/s10765011-1128-2, 2012.

Fischer, J.: Low uncertainty Boltzmann constant determinations and the kelvin redefinition, Philos. T. R. Soc. A, 374, 20150038, https://doi.org/10.1098/rsta.2015.0038, 2016.

Fischer, M.: Carbonate chemistry and $\mathrm{CaCO}_{3}$ precipitation as ikaite in Antarctic sea ice: Analysis in the Southern Ocean and off Adélie Land, Antarctica, University of Leipzig, Diploma thesis, http://hdl.handle.net/10013/epic.33808.d001 (last access: 9 June 2018), 2009.

Fofonoff, N. P.: Physical properties of sea-water, in: The Sea, edited by: Hill, M. N., Wiley, New York, 3-30, 1962.

Forch, C., Knudsen, M., and Sørensen, S. P. L.: Berichte über die Konstantenbestimmungen zur Aufstellung der hydrographischen Tabellen, D. Kgl. Danske Vidensk. Selsk. Skrifter 6. Raekke, naturvidensk. og mathem. Afd. XII, 1, 151 pp., 1902.

Gagnon, R. E., Kiefte, H., Clouter, M. J., and Whalley, E.: Pressure dependence of the elastic constants of ice Ih to $2.8 \mathrm{kbar}$ by Brillouin spectroscopy, J. Chem. Phys., 89, 4522-4528, https://doi.org/10.1063/1.454792, 1988.

Gammon, P. H., Kiefte, H., Clouter, M. J., and Denner, W.W.: Elastic constants of artificial and natural ice samples by Brillouin spectroscopy, J. Glaciol., 29, 433-460, https://doi.org/10.1021/j100244a004, 1983.

Gammon, P. H., Kiefte, H., Clouter, M. J., and Denner, W. W.: Elastic constants of ice samples by brillouin spectroscopy, J. Glaciol., 29, 433-459, https://doi.org/10.3189/S0022143000030355, 1983.

Gatley, D. P.: Understanding Psychrometrics, 2nd Edn., American Society of Heating, Refrigerating, and Air-Conditioning Engineers, Atlanta, GA, USA, 2005.

Gibbs, J. W.: Graphical methods in the thermodynamics of fluids, Transactions of the Connecticut Academy of Arts and Science, 2, 309-342, 1873a.

Gibbs, J. W.: A Method of Graphical Representation of the Thermodynamic Properties of Substances by Means of Surfaces, Transactions of the Connecticut Academy of Arts and Science, 2, 382404, $1873 b$.
Gill, A. E.: Atmosphere-Ocean Dynamics, Academic Press, San Diego, New York, Boston, London, Sydney, Tokyo, Toronto, 1982.

Gleitz, M., Rutgers van der Loeff, M. M., Thomas, D. N., Dieckmann, G. S., and Millero, F. J.: Comparison of summer and winter inorganic carbon, oxygen and nutrient concentrations in Antarctic sea ice brine, Mar. Chem., 51, 81-91, https://doi.org/10.1016/0304-4203(95)00053-T, 1995.

Goff, J. A. and Gratch, S.: Thermodynamic properties of moist air, Transactions of the American Society of Heating and Ventilating Engineers, 51, 125-164, 1945.

Goldberg, R. N. and Weir, R. D.: Conversion of temperatures and thermodynamic properties to the basis of the International Temperature Scale of 1990, Pure Appl. Chem., 64, 1545-1562, https://doi.org/10.1351/pac199264101545, 1992.

Gradshteyn, I. S. and Ryzhik, I. M.: Tables of Integrals, Series, and Products, Academic Press, San Diego, CA, 2000.

Guggenheim, E. A.: Thermodynamics, North-Holland Publishing Company, Amsterdam, 1949.

Harvey, A. H. and Huang, P. H.: First-Principles Calculation of the Air-Water Second Virial Coefficient, Int. J. Thermophys., 28, 556-565, https://doi.org/10.1007/s10765-007-0197-8, 2007.

Harvey, A. H., McLinden, M. O., and Tew, W. L.: Thermodynamic analysis and experimental study of the effect of atmospheric pressure on the ice point temperature: Its Measurement and Control in Science and Industry Proc. 9th Int. Temperature Symp., Anaheim, CA, 19-23 March 2012, vol. 8 AIP Conf. Proc. 1552, 221-226, https://doi.org/10.1063/1.4819543, 2013.

Harvey, A. H., Span, R., Fujii, K., Tanaka, M., and Davis, R. S.: Density of water: roles of the CIPM and IAPWS standards, Metrologia, 46, 196-198, https://doi.org/10.1088/00261394/46/3/006, 2009.

Hellmuth, O., Feistel, R., Lovell-Smith, J., and Kalova, J.: Metrological aspects of humidity: state of discussion on common positions, challenges, and needs, Technical Report of the Joint BIPM CCT-WG6/CCQM \& JCS Workshop on Hygrometry, 16th Int. Conf. on the Properties of Water and Steam (Greenwich, UK, 2013), available at: http://www.teos-10.org/JCS.htm (last access: 9 June 2018), 2014.

Hellmuth, O., Feistel, R., Lovell-Smith, J., Kalova, J., Kretzschmar, H.-J., and Herrmann, S.: Determination of the Properties of Humid Air using the Thermodynamic Equation of Seawater TEOS10, Wissenschaftliche Mitteilungen des Instituts für Meteorologie der Universität Leipzig, in press, 2018.

Herrmann, S., Kretzschmar, H.-J., and Gatley, D. P.: Thermodynamic properties of real moist air, dry air, steam, water, and ice, ASHRAE RP-1485 (Atlanta, GA: American Society of Heating, Refrigerating and Air-Conditioning Engineers Inc.), https://doi.org/10.1080/10789669.2009.10390874, 2017.

Hobbs, P. V.: Ice Physics, Clarendon Press, Oxford, 1974.

Hyland, R. W. and Wexler, A.: Formulations for the thermodynamic properties of dry air from $173.15 \mathrm{~K}$ to $473.15, \mathrm{~K}$, and of saturated moist air from $173.15 \mathrm{~K}$ to $372.15 \mathrm{~K}$, at pressures up to $5 \mathrm{MPa}$, ASHRAE Tran., 89, 520-535, 1983.

IAPSO: IAPSO Annual Reports, 2005 IAPSO Activities, available at: http://iapso.iugg.org/home-iapso8/iapso-annual-reports. html?showall=\&star=12 (last access: 9 June 2018), 2005.

IAPWS: Minutes from 2005 IAPWS Meeting, IAPWS Thermophysical Properties of Water and Steam WG, Santorini, Greece, 
4-8 July 2005, available at: http://www.iapws.org/minutes/2005. html (last access: 10 June 2018), 2005.

IAPWS: Minutes from 2007 IAPWS Meeting, IAPWS Thermophysical Properties of Water and Steam WG, Lucerne, Switzerland, 27-30 August 2007, available at: http://www.iapws.org/ minutes/2007.html (last access: 8 June 2018), 2007.

IAPWS: Minutes of the Meetings of the Executive Committee of the International Association for the Properties of Water and Steam, Berlin, Germany, 7-12 September 2008, available at: http://www.iapws.org/minutes/2008/ ContentsandECMinutes2008.pdf (last access: 10 June 2018), 2008.

IAPWS: Minutes of the Meetings of the Executive Committee of the International Association for the Properties of Water and Steam held in Boulder, Colorado, 30 September-5 October 2012, available at: http://www.iapws.org/minutes/2012/ ECMinutes2012.pdf (last access: 10 June 2018), 2012.

IAPWS: Press Release 16th Int. Conf. on the Properties of Water and Steam and Int. Association for the Properties of Water and Steam 2013 Meeting, available at: www.iapws.org/news/ Press2013.pdf (last access: 10 June 2018), 2013.

IAPWS AN4-09: Advisory Note No. 4: Roles of IAPWS and CIPM Standards for the Density of Water (Doorwerth, The Netherlands: The International Association for the Properties of Water and Steam), available at: http://www.iapws.org (last access: 10 June 2018), 2009.

IAPWS AN5-13: Advisory Note No. 5: Industrial Calculation of the Thermodynamic Properties of Seawater (Dresden, Germany: The International Association for the Properties of Water and Steam), available at: http://www.iapws.org (last access: 10 June 2018), 2016.

IAPWS AN6-16: Advisory Note No. 6: Relationship between Various IAPWS Documents and the International Thermodynamic Equation of Seawater - 2010 (TEOS-10) (Dresden, Germany: The International Association for the Properties of Water and Steam), available at: http://www.iapws.org (last access: 10 June 2018), 2016.

IAPWS G11-15: Guideline on a Virial Equation for the Fugacity of $\mathrm{H}_{2} \mathrm{O}$ in Humid Air (Stockholm, Sweden: The International Association for the Properties of Water and Steam), available at: http://www.iapws.org (last access: 10 June 2018), 2015.

IAPWS G12-15: Guideline on Thermodynamic Properties of Supercooled Water (Stockholm, Sweden: The International Association for the Properties of Water and Steam), available at: http://www.iapws.org (last access: 10 June 2018), 2015.

IAPWS G5-01: Guideline on the Use of Fundamental Physical Constants and Basic Constants of Water (Dresden, Germany: The International Association for the Properties of Water and Steam), available at: http://www.iapws.org (last access: 10 June 2018), 2016.

IAPWS G8-10: Guideline on an Equation of State for Humid Air in Contact with Seawater and Ice, Consistent with the IAPWS Formulation 2008 for the Thermodynamic Properties of Seawater (Niagara Falls, Canada: The International Association for the Properties of Water and Steam), available at: http://www.iapws. org (last access: 10 June 2018), 2010.

IAPWS G11-15: Guideline on a Virial Equation for the Fugacity of $\mathrm{H}_{2} \mathrm{O}$ in Humid Air (Stockholm, Sweden: The International
Association for the Properties of Water and Steam), available at: http://www.iapws.org (last access: 10 June 2018), 2015.

IAPWS G9-12: Guideline on a Low-Temperature Extension of the IAPWS-95 Formulation for Water Vapor (Boulder, Colorado, USA: The International Association for the Properties of Water and Steam), available at: http://www.iapws.org (last access: 10 June 2018), 2012.

IAPWS R13-08: Release on the IAPWS Formulation 2008 for the Thermodynamic Properties of Seawater, Berlin, Germany: The International Association for the Properties of Water and Steam, available at: http://www.iapws.org (last access: 10 June 2018), 2008.

IAPWS R10-06: Revised Release on the Equation of State 2006 for $\mathrm{H}_{2} \mathrm{O}$ Ice Ih (Doorwerth, The Netherlands: The International Association for the Properties of Water and Steam), available at: http://www.iapws.org (last access: 10 June 2018), 2009.

IAPWS R14-08: Revised Release on the Pressure along the Melting and Sublimation Curves of Ordinary Water Substance (Plzeň, Czech Republic: The International Association for the Properties of Water and Steam), available at: http://www.iapws.org (last access: 10 June 2018), 2011.

IAPWS R6-95: Revised Release on the IAPWS Formulation 1995 for the Thermodynamic Properties of Ordinary Water Substance for General and Scientific Use (Dresden, Germany: The International Association for the Properties of Water and Steam), available at: http://www.iapws.org (last access: 10 June 2018), 2016.

IAPWS SR1-86: Revised Supplementary Release on Saturation Properties of Ordinary Water Substance (St. Petersburg, Russia: The International Association for the Properties of Water and Steam), available at: http://www.iapws.org (last access: 10 June 2018), 1992.

IAPWS SR6-08: Revised Supplementary Release on Properties of Liquid Water at 0.1 MPa (Plzeň, Czech Republic: The International Association for the Properties of Water and Steam), available at: http://www.iapws.org (last access: 10 June 2018), 2011.

IAPWS SR7-09: Supplementary Release on a Computationally Efficient Thermodynamic Formulation for Liquid Water for Oceanographic Use (Doorwerth, The Netherlands: The International Association for the Properties of Water and Steam), available at: http://www.iapws.org (last access: 10 June 2018), 2009.

IOC: Intergovernmental Oceanographic Commission, Twenty-fifth Session of the Assembly, Paris, 16-25 June 2009. Resolution XXV-7, INTERNATIONAL THERMODYNAMIC EQUATION OF SEAWATER (TEOS-10) Part I, available at: http: //unesdoc.unesco.org/images/0018/001878/187890e.pdf (last access: 10 June 2018), 2009.

IOC, SCOR, IAPSO: The international thermodynamic equation of seawater - 2010: Calculation and use of thermodynamic properties, Intergovernmental Oceanographic Commission, Manuals and Guides No. 56, UNESCO (English), 196 pp., Paris, available at: http://www.TEOS-10.org (last access: 10 June 2018), 2010.

IPCC: Climate Change 2013: The Physical Science Basis. Contribution of Working Group I to the Fifth Assessment Report of the Intergovernmental Panel on Climate Change, edited by: Stocker, T. F., Qin, D., Plattner, G.-K., Tignor, M., Allen, S. K., Boschung, J., Nauels, A., Xia, Y., Bex, V., and Midgley, P. M., Cambridge University Press, Cambridge, United Kingdom and New York, NY, USA, 1535 pp., available at: http://www.ipcc.ch/report/ar5/ wg1/ (last access: 10 June 2018), 2013. 
IUGG: Int. Union of Geodesy and Geophysics, XXV General Assembly, Melbourne, Australia, Comptes Rendus, available at: www.iugg.org/assemblies/2011melbourne/ (last access: 10 June 2018), 27 June-7 July 2011.

Jackett, D. R., McDougall, T. J., Feistel, R., Wright, D. G., and Griffies, S. M.: Algorithms for Density, Potential Temperature, Conservative Temperature, and the Freezing Temperature of Seawater, J. Atmos. Ocean. Tech., 23, 1706-1728, 2006.

Jacobsen, J. P. and Knudsen, M.: Urnormal 1937 or primary standard sea-water 1937, Assoc. Oceanog. Phys., Pub. Sci., No. 7, 38 pp., 1940.

Jacobson, M. Z.: Fundamentals of Atmospheric Modeling, 2nd edn., Cambridge University Press, Cambridge, 2005.

Josey, S. A., Gulev, S., and Yu, L.: Exchanges Through the Ocean Surface, in: Ocean Circulation and Climate, edited by: Siedler, G., Griffies, S. M., Gould, J., and Church, J. A., A 21st Century Perspective, Elsevier, Amsterdam, 115-140, 2013.

Justice, J.-C.: Ionic Interactions in Solution: VI. The Activity Expansion and the Association Concept, J. Solution Chem., 20, 1017-1029, https://doi.org/10.1007/BF00664000, 1991.

Kaplan, W.: Advanced Calculus, Addison-Wesley, Reading, MA, 1984.

Kell, G. S.: Density, thermal expansibility and compressibility of liquid water from 0 to $150 \mathrm{C}$ : corrections and tables for atmospheric pressure and saturation reviewed and expressed on 1968 temperature scale, J. Chem. Eng. Data, 20, 97-105, https://doi.org/10.1021/je60064a005, 1975.

Knudsen, M.: On the standard-water used in the hydrographical research until July 1903, Tech. rep., Conseil permanent international pour l'exploration de la mer, Publications de circonstance no. 2, 1903.

Kraus, E. B. and Businger, J. A.: Atmosphere-Ocean Interaction, Oxford University Press/Clarendon, New York, Oxford, 1994.

Kremling, K.: New method for measuring density of seawater, Nature, 229, 109-110, https://doi.org/10.1038/229109a0, 1971.

Kretzschmar, H.-J., Feistel, R., Wagner, W., Miyagawa, K., Harvey, A. H., Cooper, J. R., Hiegemann, M., Blangetti, F., Orlov, K., Weber, I., Singh, A., and Herrmann, S.: The IAPWS Industrial Formulation for the Thermodynamic Properties of Seawater, Desalin. Water Treat., 55, 1177-1199, https://doi.org/10.1080/19443994.2014.925838, 2015.

Krümmel, O.: Handbuch der Ozeanographie, Band I, Verlag von J. Engelhorn, Stuttgart, 1907.

Kwiecinski, B.: The relation between the chlorinity and the conductivity in Baltic water, Deep-Sea Res., 12, 113-120, https://doi.org/10.1016/0011-7471(65)90017-3, 1965.

Lacis, A. A., Schmidt, G. A., Rind, D., and Ruedy, R. A.: Atmospheric $\mathrm{CO}_{2}$ : Principal Control Knob Governing Earth's Temperature, Science, 330, 356-359, https://doi.org/10.1126/science.1190653, 2010.

Lago, S., Giuliano Albo, P. A., von Rohden, C., and Rudtsch, S.: Speed of sound measurements in North Atlantic Seawater and IAPSO Standard Seawater up to $70 \mathrm{MPa}$, Mar. Chem., 177, 662667, https://doi.org/10.1016/j.marchem.2015.10.007, 2015.

Landau, L. D. and Lifschitz, E. M.: Statistische Physik. AkademieVerlag, Berlin, 1966.

Lemmon, E. W., Jacobsen, R. T., Penoncello, S. G., and Friend, D. G.: Thermodynamic Properties of Air and Mixtures of Nitrogen, Argon and Oxygen From 60 to $2000 \mathrm{~K}$ at Pres- sures to $2000 \mathrm{MPa}$, J. Phys. Chem. Ref. Data, 29, 331-362, https://doi.org/10.1063/1.1285884, 2000.

Le Quéré, C., Moriarty, R., Andrew, R. M., Peters, G. P., Ciais, P., Friedlingstein, P., Jones, S. D., Sitch, S., Tans, P., Arneth, A., Boden, T. A., Bopp, L., Bozec, Y., Canadell, J. G., Chini, L. P., Chevallier, F., Cosca, C. E., Harris, I., Hoppema, M., Houghton, R. A., House, J. I., Jain, A. K., Johannessen, T., Kato, E., Keeling, R. F., Kitidis, V., Klein Goldewijk, K., Koven, C., Landa, C. S., Landschützer, P., Lenton, A., Lima, I. D., Marland, G., Mathis, J. T., Metzl, N., Nojiri, Y., Olsen, A., Ono, T., Peng, S., Peters, W., Pfeil, B., Poulter, B., Raupach, M. R., Regnier, P., Rödenbeck, C., Saito, S., Salisbury, J. E., Schuster, U., Schwinger, J., Séférian, R., Segschneider, J., Steinhoff, T., Stocker, B. D., Sutton, A. J., Takahashi, T., Tilbrook, B., van der Werf, G. R., Viovy, N., Wang, Y.-P., Wanninkhof, R., Wiltshire, A., and Zeng, N.: Global carbon budget 2014, Earth Syst. Sci. Data, 7, 47-85, https://doi.org/10.5194/essd-7-47-2015, 2015.

Lewis, E. L.: The Practical Salinity Scale 1978 and its antecedents, IEEE J. Oceanic Eng., OE-5, 3-8, https://doi.org/10.1109/JOE.1980.1145448, 1980.

Lewis, E. L. and Perkin, R. G.: Salinity: Its definition and calculation, J. Geophys. Res., 83, 466-478, https://doi.org/10.1029/JC083iC01p00466, 1978.

Lewis, G. N.: The law of physico-chemical change, P. Am. Acad. Arts Sci., 37, 49-69, https://doi.org/10.2307/20021635,1901.

Lewis, G. N. and Randall, M.: Thermodynamics and the Free Energy of Chemical Substances, MacGraw-Hill Book Company, New York, 1923.

Linke, F. and Baur, F.: Meteorologisches Taschenbuch, Akademische Verlagsgesellschaft Geest \& Portig, Leipzig, 1970.

Logan, B. W. and Cebulsk, D. E.: Sedimentary environments of Shark Bay, Western Australia, in: Carbonate Sedimentation and Environments, Shark Bay, Western Australia, Memoir No. 13, The American Association of Petroleum Geologists, 1-37, 1970.

Lovell-Smith, J. W., Feistel, R., Harvey, A. H., Hellmuth, O., Bell, S. A., Heinonen, M., and Cooper, J. R.: Metrological challenges for measurements of key climatological observables. Part 4: atmospheric relative humidity, Metrologia, 53, R40-R59, https://doi.org/10.1088/0026-1394/53/1/R40, 2016.

Lübken, F.-J., Lautenbach, J., Höffner, J., Rapp, M., and Zecha, M.: First continuous temperature measurements within polar mesosphere summer echoes, J. Atmos. Sol.-Terr. Phys., 71, 453-463, https://doi.org/10.1016/j.jastp.2008.06.001, 2009.

Lyman, J.: Redefinition of salinity and chlorinity, Limnol. Oceanogr., 14, 928-929, https://doi.org/10.4319/lo.1969.14.6.0928, 1969.

Margenau, H. and Murphy, G. M.: The Mathematics of Physics and Chemistry, D. van Nostrand Company, Inc., New York, 1943.

Marion, G. M. and Grant, S. A.: FREZCHEM: A ChemicalThermodynamic Model for Aqueous Solutions at Subzero Temperatures, CRREL Special Report 94-18, U.S. Army Corps of Engineers, Cold Regions Research \& Engineering Laboratory, Hanover, NH, https://doi.org/10.1016/j.marchem.2011.04.002, 1994.

Marion, G. M. and Kargel, J. S.: Cold Aqueous Planetary Geochemistry with FREZCHEM: From Modeling to the Search for Life at the Limits, Springer, Berlin/Heidelberg, 2008.

Marion, G. M., Millero, F. J., and Feistel, R.: Precipitation of solid phase calcium carbonates and their effect on applica- 
tion of seawater $S_{A}-T-P$ models, Ocean Sci., 5, 285-291, https://doi.org/10.5194/os-5-285-2009, 2009.

Marion, G. M., Millero, F. J., Camões, F., Spitzer, P., Feistel, R., and Chen, C.-T. A.: pH of Seawater, Mar. Chem., 126, 89-96, 2011.

McDougall, T. J.: Potential enthalpy: A conservative oceanic variable for evaluating heat content and heat fluxes, J. Phys. Oceanogr., 33, 945-963, https://doi.org/10.1175/15200485(2003)033<945:PEACOV>2.0.CO;2, 2003.

McDougall, T. J. and Feistel, R.: What causes the adiabatic lapse rate? Deep-Sea Res. Pt. I, 50, 1523-1535, https://doi.org/10.1016/j.dsr.2003.09.007, 2003.

McDougall, T. J., Jackett, D. R., Wright, D. G., and Feistel, R.: Accurate and computationally efficient algorithms for potential temperature and density of seawater, J. Atmos. Ocean. Tech., 20, 730-741, https://doi.org/10.1175/15200426(2003)20<730:AACEAF>2.0.CO;2, 2003.

McDougall, T. J. and Barker, P. M.: Getting started with TEOS10 and the Gibbs Seawater (GSW) Oceanographic Toolbox, SCOR/IAPSO WG127, ISBN 978-0-646-55621-5, 28 pp., 2011.

McDougall, T. J., Chen, C.-T. A., Feistel, R., Gramm-Osipova, V. N., Jackett, D. R., King, B. A., Marion, G. M., Spitzer, P., Wright, D., and Tremaine, P.: Improved seawater thermodynamics: How should the proposed change in salinity be implemented?, DGMMitteilungen, 3-4, 2-7, 2008.

McDougall, T. J., Jackett, D. R., Millero, F. J., Pawlowicz, R., and Barker, P. M.: A global algorithm for estimating Absolute Salinity, Ocean Sci., 8, 1123-1134, https://doi.org/10.5194/os-81123-2012, 2012.

McDougall, T. J., Feistel, R., and Pawlowicz, R.: Thermodynamics of Seawater, in: Ocean Circulation and Climate, A 21st Century Perspective, edited by: Siedler, G., Griffies, S. M., Gould, J., and Church, J. A., Academic Press/Elsevier, Oxford/Amsterdam, 141-158, 2013.

Millero, F. J.: The physical chemistry of estuaries, in: Marine Chemistry in the Coastal Environment, edited by: Church, T. M., American Chemical Society, 25-55, 1975.

Millero, F. J.: Effects of changes in the composition of seawater on the density-salinity relationship, Deep-Sea Res. Pt. 1, 47, 15831590, https://doi.org/10.1016/S0967-0637(99)00104-1, 2000a.

Millero, F. J.: The Equation of State of Lakes, Aquat. Geochem., 6, 1-17, https://doi.org/10.1023/A:1009626325650, 2000b.

Millero, F. J.: The thermodynamics of seawater. Part I. The PVT properties, Ocean Phys. Eng., 7, 403-460, 1982.

Millero, F. J.: The Thermodynamics of Seawater. Part II. Thermochemical Properties, Ocean Phys. Eng., 8, 1-40, 1983.

Millero, F. J.: What is psu?, Oceanography, 6, p. 67, 1993.

Millero, F. J. and Huang, F.: The density of seawater as a function of salinity ( 5 to $70 \mathrm{~g} \mathrm{~kg}^{-1}$ ) and temperature (273.15 to 363.15 K), Ocean Sci., 5, 91-100, https://doi.org/10.5194/os-591-2009, 2009.

Millero, F. J. and Huang, F.: The compressibility of seawater from 0 to $95^{\circ} \mathrm{C}$ at $1 \mathrm{~atm}$, Mar. Chem., 126, 149-154, https://doi.org/10.1016/j.marchem.2011.05.003, 2011.

Millero, F. J. and Leung, W. H.: The thermodynamics of seawater at one atmosphere, Am. J. Sci., 276, 1035-1077, https://doi.org/10.2475/ajs.276.9.1035, 1976.

Millero, F. J. and Kremling, K.: The densities of Baltic Sea waters, Deep-Sea Res., 23, 1129-1138, https://doi.org/10.1016/00117471(76)90889-5, 1976.
Millero, F. J. and Li, X.: Comments on "On equations for the speed of sound in seawater" [J. Acoust. Soc. Am. 94, 255-275 (1993)], J. Acoust. Soc. Am., 95, 2757-2759, https://doi.org/10.1121/1.409844, 1994.

Millero, F. J., Gonzales, A., Brewer, P. G., and Bradshaw, A.: The density of North Atlantic and North Pacific deep waters, Earth Planet. Sc. Lett., 32, 468-472, https://doi.org/10.1016/0012821X(76)90087-X, 1976.

Millero, F. J., Feistel, R., Wright, D. G., and McDougall, T. J.: The composition of Standard Seawater and the definition of the Reference-Composition Salinity Scale, Deep-Sea Res. Pt. I, 55, 50-72, https://doi.org/10.1016/j.dsr.2007.10.001, 2008.

Millero, F. J., Waters, J., Woosley, R., Huang, F., and Chanson, M.: The effect of composition on the density of Indian Ocean waters, Deep-Sea Res. Pt. I, 55, 460-470, https://doi.org/10.1016/j.dsr.2008.01.006, 2008.

Millero, F. J., Huang, F., Williams, N., Waters, J., and Woosley, R.: The effect of composition on the density of South Pacific Ocean waters, Mar. Chem., 114, 56-62, https://doi.org/10.1016/j.marchem.2009.04.001, 2009.

Millero, F. J., Huang, F., Woosley, R. J., Letscher, R. T., and Hansell, D. A.: Effect of dissolved organic carbon and alkalinity on the density of Arctic Ocean waters, Aquat. Geochem., 17, 311-326, https://doi.org/10.1007/s10498-010-9111-2, 2011.

Mulligan, J. F. and Hertz, G. G.: An unpublished lecture by Heinrich Hertz: "On the energy balance of the Earth", Am. J. Phys., 65, 36-45, https://doi.org/10.1119/1.18565, 1997.

Murphy, D. M. and Koop, T.: Review of the vapour pressures of ice and supercooled water for atmospheric applications, Q. J. Roy. Meteor. Soc., 131, 1539-1565, https://doi.org/10.1256/qj.04.94, 2005.

Nayar, K. G., Sharkawy, M. H., Banchik, L. D., and Lienhard, V. J. H.: Thermophysical properties of seawater: A review and new correlations that include pressure dependence, Desalination, 390 , 1-24, https://doi.org/10.1016/j.desal.2016.02.024, 2016.

Nesbitt, H. W.: A Consistency Test for Single Ion Activity Coefficients in Electrolyte Solutions, Including Seawater, Chem. Geol., 29, 107-116, https://doi.org/10.1016/00092541(80)90008-X, 1980.

OMI: Values of some physical functions and constants used in meteorology, Definitions and specifications of water vapour in the atmosphere, Organisation Météorologique Internationale, Publication 79, Lausanne, 1951.

Pátek, J., Hrubý, J., Klomfar, J., Součková, M., and Harvey, A. H.: Reference correlations for thermophysical properties of liquid water at 0.1 MPa, J. Phys. Chem. Ref. Data, 38, 21-29, 2009.

Pawlowicz, R.: Calculating the Conductivity of Natural Waters, Limnol. Oceanogr.-Meth., 4, 489-501, https://doi.org/10.4319/lom.2008.6.489, 2008.

Pawlowicz, R.: A model for predicting changes in the electrical conductivity, practical salinity, and absolute salinity of seawater due to variations in relative chemical composition, Ocean Sci., 6, 361-378, https://doi.org/10.5194/os-6-361-2010, 2010.

Pawlowicz, R. and Feistel, R.: Limnological applications of the Thermodynamic Equation of Seawater 2010 (TEOS-10), Limnol. Oceanogr.-Meth., 10, 853-867, https://doi.org/10.4319/lom.2012.10.853, 2012.

Pawlowicz, R., McDougall, T., Feistel, R., and Tailleux, R.: Preface "An historical perspective on the development of the Thermody- 
namic Equation of Seawater - 2010”, Ocean Sci., 8, 161-174, https://doi.org/10.5194/os-8-161-2012, 2012.

Pawlowicz, R., Feistel, R., and McDougall, T. J.: SCOR/IAPSO/IAPWS Joint Committee on Seawater, available at: http://www.scor-int.org/JCS.htm (last access: 10 June 2018), 2014.

Pawlowicz, R., Feistel, R., McDougall, T. J., Ridout, P., Seitz, S., and Wolf, H.: Metrological challenges for measurements of key climatological observables, Part 2: Oceanic salinity, Metrologia, 53, R12-R25, https://doi.org/10.1088/0026-1394/53/1/R12, 2016.

Penny, A. H.: A theoretical determination of the elastic constants of ice, Proc. Camb. Phil. Soc. Math. Phys. Sci., 44, 423-439, 1948.

Petrenko, V. F. and Whitworth, R. W.: Physics of Ice, Oxford University Press, Oxford, 1999.

Picard, A., Davis, R. S., Gläser, M., and Fujii, K.: Revised formula for the density of moist air (CIPM-2007), Metrologia, 45, 14955, https://doi.org/10.1088/0026-1394/45/2/004, 2008.

Pierrehumbert, R. T.: Principles of Planetary Climate, Cambridge University Press, Cambrige, 2010.

Prausnitz, J. M., Lichtenthaler, R. N., and de Azevedo, E. G.: Molecular Thermodynamics of Fluid-Phase Equilibria, 3rd edn., Prentice Hall, Upper Saddle River, NJ, 1999.

Preston-Thomas, H.: The International Temperature Scale of 1990 (ITS-90), Metrologia, 27, 3-10, 1990.

Pruppacher, H. R. and Klett, J. D.: Microphysics of Clouds and Precipitation, Second Revised and Enlarged Edition with an Introduction to Cloud Chemistry and Cloud Electricity, Kluwer Academic Publishers, Dordrecht, Boston, MA, London, 1997.

PTB: The new International System of Units (SI), PhysikalischTechnische Bundesanstalt, Braunschweig, 2017.

Reid, P. C. and Valdés, L.: ICES status report on climate change in the North Atlantic, ICES Cooperative Research Report 310, ICES, Copenhagen, 2011.

Rogers, R. R. and Yau, M. K.: Short Course in Cloud Physics, 3rd edn., Butterworth-Heinemann, Oxford, 1989.

Rohde, K.-H.: Untersuchungen über die Calcium- und Magnesiumanomalie in der Ostsee, Beitr. Meereskunde, 19, 18-31, 1966.

Roquet, F., Madec, G., McDougall, T. J., and Barker, P. M.: Accurate polynomial expressions for the density and specific volume of seawater using the TEOS-10 standard, Ocean Model., 90, 2943, https://doi.org/10.1016/j.ocemod.2015.04.002, 2015.

Rusby, R. L.: The conversion of thermal reference values to the ITS-90, J. Chem. Thermodyn., 23, 1153-1161, https://doi.org/10.1016/S0021-9614(05)80148-X, 1991.

Rusby, R. L., Hudson, R. P., and Durieux, M.: Revised Values for $\left(t_{90}-t_{68}\right)$ from $630^{\circ} \mathrm{C}$ to $1064^{\circ} \mathrm{C}$, Metrologia, 31, 149-153, https://doi.org/10.1088/0026-1394/31/2/009, 1994.

Safarov, J., Millero, F., Feistel, R., Heintz, A., and Hassel, E.: Thermodynamic properties of standard seawater: extensions to high temperatures and pressures, Ocean Sci., 5, 235-246, https://doi.org/10.5194/os-5-235-2009, 2009.

Safarov, J., Millero, F. J., Feistel, R., Heintz, A., and Hassel, E. P.: Pressure, Density, and Temperature Properties and Vapor Pressure of Seawater in Various Salinities, Chem.-Ing.-Tech., 82, 1587-1587, https://doi.org/10.1002/cite.201050649m 2010.

Safarov, J., Berndt, S., Millero, F. J., Feistel, R., Heintz, A., and Hassel, E. P.: $(p, \rho, T)$ properties of seawater: Exten- sions to high salinities, Deep-Sea Res. Pt. I, 65, 146-156, https://doi.org/10.1016/j.dsr.2012.03.010, 2012.

Safarov, J., Berndt, S., Millero, F.J., Feistel, R., Heintz, A., and Hassel, E. P.: $(p, \rho, T)$ Properties of seawater at brackish salinities: Extensions to high temperatures and pressures, Deep-Sea Res. Pt. I, 78, 95-101, https://doi.org/10.1016/j.dsr.2013.04.004, 2013.

Saunders, P.: The International Temperature Scale of 1990, ITS-90, WOCE Newsletter, 10, available at: https://www.nodc.noaa.gov/ woce/wdiu/wocedocs/newsltr/news10/contents.htm (last access: 10 June 2018), 1990.

Schmidt, G. A., Ruedy, R. A., Miller, R. L., and Lacis, A. A.: The attribution of the present-day total greenhouse effect, J. Geophys. Res., 115, D20106, https://doi.org/10.1029/2010JD014287, 2010.

Schmidt, H., Wolf, H., and Hassel, E.: A method to measure the density of seawater accurately to the level of $10^{-6}$, Metrologia, 53, 770-786, https://doi.org/10.1088/0026-1394/53/2/770, 2016.

Schmidt, H., Seitz, S., Hassel, E., and Wolf, H.: The densitysalinity relation of standard seawater, Ocean Sci., 14, 15-40, https://doi.org/10.5194/os-14-15-2018, 2018.

Schulson, E. M.: The structure and mechanical behavior of ice, Memb. J. Min. Met. Mat. Soc., 51, 21-27, https://doi.org/10.1007/s11837-999-0206-4, 1999.

SCOR: SCOR Electronic Newsletter \#4, October 2005, available at: http://www.scor-int.org/Publications/SCOR-NL-4.pdf (last access: 10 June 2018), 2005.

Seitz, S., Spitzer, P. and Brown, R. J. C.: CCQM-P111 study on traceable determination of practical salinity and mass fraction of major seawater components, Accredit. Qual. Assur. 15, 9-17, https://doi.org/10.1007/s00769-009-0578-8, 2010.

Seitz, S., Feistel, R., Wright, D. G., Weinreben, S., Spitzer, P., and De Bièvre, P.: Metrological traceability of oceanographic salinity measurement results, Ocean Sci., 7, 45-62, https://doi.org/10.5194/os-7-45-2011, 2011.

Sharqawy, M. H., Lienhard, J. H., and Zubair, S. M.: Thermophysical properties of seawater: a review of existing correlations and data, Desalin. Water Treat., 16, 354-380, https://doi.org/10.5004/dwt.2010.1079, 2010.

Sharp, J. D., Albehadili, M. H. M., Millero, F. J., and Woosley, R. J.: Estimating the Density and Compressibility of Natural Hypersaline Brines Using the Pitzer Ionic Interaction Model, Aquat. Geochem., 21, 11-29, https://doi.org/10.1007/s10498-015-92524, 2015.

Shaw, A. N.: The Derivation of Thermodynamical Relations for a Simple System, Philos. T. Roy. Soc. Lond. A, 234, 299-328, https://doi.org/10.1098/rsta.1935.0009, 1935.

Sherwood, S. C., Ingram, W., Tsushima, Y., Satoh, M., Roberts, M., Vidale, P. L., and O'Gorman, P. A.: Relative humidity changes in a warmer climate, J. Geophys. Res., 115, D09104, https://doi.org/10.1029/2009JD012585, 2010.

Siedler, G.: SI units in oceanography, Berichte aus dem Institut für Meereskunde an der Christian-Albrechts-Universität Kiel, Nr. $101,1998$.

Siedler, G. and Peters, H.: Properties of seawater, in: LandoltBörnstein New Series V/3a, Oceanography, edited by: Sündermann, J., Springer-Verlag, Berlin, Heidelberg, New York, London, Paris, Tokyo, Hong Kong, 233-264, 1986. 
Sörensen, S. P. L.: Enzymstudien. II. Mitteilung, Über die Messung und die Bedeutung der Wasserstoffionenkonzentration bei enzymatischen Prozessen, Biochem. Z., 21, 131-304, 1909.

Sørensen, S. P. L. and Linderstrøm-Lang, K. U.: On the Determination and Value of $\pi_{0}$ in Electrometric Measurement of HydrogenIon Concentration, Comptes rendus des travaux du laboratoire Carlsberg, 15, 1-40, 1924.

Sörensen, S. P. L. and Palitzsch, S.: Über die Messung der Wasserstoffionenkonzentration des Meerwassers, Biochem. Z., 24, 387415,1910

Sonntag, D.: Hygrometrie, Akademie-Verlag, Berlin, 1966.

Spitzer, P., Fisicaro, P., Meinrath, G., and Stoica, D.: pH buffer assessment and Pitzer's equations, Accredit. Qual. Assur., 16, 191198, https://doi.org/10.1007/s00769-010-0743-0, 2011.

Stevens, B. and Bony, S.: What Are Climate Models Missing?, Science, 340, 1053-1054, https://doi.org/10.1126/science.1237554, 2013.

Sverdrup, H. U., Johnson, M. W., and Fleming, R. H.: The Oceans, their Physics, Chemistry and General Biology, Prentice-Hall Inc., New York, 1942.

Tanaka, M., Girard, G., Davis, R., Peuto, A., and Bignell, N.: Recommended table for the density of water between $0{ }^{\circ} \mathrm{C}$ and $40^{\circ} \mathrm{C}$ based on recent experimental reports, Metrologia, 38, 301-309, https://doi.org/10.1088/0026-1394/38/4/3, 2001.

Tillner-Roth, R.: Fundamental Equations of State, Shaker Verlag, Aachen, 1998.

Tollefsen, J.: A break in the clouds, Nature, 485, 164-166, https://doi.org/10.1038/485164a, 2012.

Trenberth, K. E., Jones, P. D., Ambenje, P., Bojariu, R., Easterling, D., Klein Tank, A., Parker, D., Rahimzadeh, F., Renwick, J. A., Rusticucci, M., Soden, B., and Zhai, P.: Observations: Surface and Atmospheric Climate Change, in: Climate Change 2007: The Physical Science Basis. Contribution of Working Group I to the Fourth Assessment Report of the Intergovernmental Panel on Climate Change, Cambridge University Press, edited by: Solomon, S., Qin, D., Manning, M., Chen, Z., Marquis, M., Averyt, K. B., Tignor M., and Miller, H. L., Cambridge, United Kingdom and New York, NY, USA, available at: http://www.ipcc.ch/pdf/assessment-report/ar4/wg1/ ar4-wg1-chapter3-supp-material.pdf (last access: 11 June 2018), 2007.

Tsunogai, S., Kusakabe, M., Iizumi, H., Koike, I., and Hattori, A.: Hydrographic features of the deep water of the Bering Sea - the Sea of Silica, Deep-Sea Res., 26, 641-659, https://doi.org/10.1016/0198-0149(79)90038-4, 1979.

Turner, D. R., Achterberg, E. P., Chen, C.-T. A., Clegg, S. L., Hatje, V., Maldonado, M. T., Sander, S. G., van den Berg, C. M. G., and Wells, M.: Toward a Quality-Controlled and Accessible Pitzer Model for Seawater and Related Systems, Frontiers in Marine Science, 3, 139, https://doi.org/10.3389/fmars.2016.00139, 2016.

Uchida, H., Kawano, T., Aoyama, M., and Murata, A.: Absolute salinity measurements of standard seawaters for conductivity and nutrients, La mer, 49, 119-126, available at: http://www. sfjo-lamer.org/la_mer/49-3_4/49-3-4-5.pdf (last access: 11 June 2018), 2011.

Unesco: Collected reports of the joint panel on oceanographic tables and standards, 1964-1969, Unesco Technical Paper Marine Science, 27, UNESCO, Paris, 1976.
Unesco: The Practical Salinity Scale 1978 and the International Equation of State of Seawater 1980. Tenth report of the joint panel on oceanographic tables and standards, Unesco Technical Paper Marine Science, 36, UNESCO, Paris, available at: http:// unesdoc.unesco.org/images/0004/000461/046148eb.pdf (last access: 11 June 2018), 1981a.

Unesco: Background papers and supporting data on the International Equation of State of Sea water 1980, Unesco Technical Paper Marine Science, 38, UNESCO, Paris, available at: http:// unesdoc.unesco.org/images/0004/000479/047932eb.pdf (last access: 11 June 2018), 1981 b.

Unesco: Background papers and supporting data on the Practical Salinity Scale 1978, Unesco Technical Paper Marine Science, 37, UNESCO, Paris, 1981c.

Unesco: Algorithms for computation of fundamental properties of seawater, Unesco Technical Papers in Marine Science, 44, UNESCO, Paris, available at: http://unesdoc.unesco.org/images/ 0005/000598/059832eb.pdf (last access: 11 June 2018), 1983.

Unesco: The International System of Units (SI) in Oceanography, Unesco Technical Papers in Marine Science, 45, UNESCO, Paris, 1985.

Unesco: Progress on oceanographic tables and standards 1983-1986: Work and recommendations of the Unesco/SCOR/ICES/IAPSO Joint Panel, Unesco Technical Papers in Marine Science, 50, UNESCO, Paris, 1986.

Valladares, J., Fennel, W., and Morozov, E. G.: Announcement: Replacement of EOS-80 with the International Thermodynamic Equation of Seawater - 2010 (TEOS-10), Deep-Sea Res., 58, p. 978, https://doi.org/10.1016/j.dsr.2011.07.005, 2011a.

Valladares, J., Fennel, W., and Morozov, E. G.: Announcement: Replacement of EOS-80 with the International Thermodynamic Equation of Seawater - 2010 (TEOS-10), Ocean Model., 40, p. 1, https://doi.org/10.1016/S1463-5003(11)00154-5, 2011 b.

VIM3: International Vocabulary of Metrology - Basic and General Concepts and Associated Terms, VIM 3rd edn., JCGM 200, available at: https://www.bipm.org/en/publications/guides/ vim.html (last access: 11 June 2018), 2012.

Von Rohden, C., Fehres, F., and Rudtsch, S.: Capability of pure water calibrated time-of-flight sensors for the determination of speed of sound in seawater, J. Acoust. Soc. Am., 138, 651-662, https://doi.org/10.1121/1.4926380, 2015.

von Rohden, C., Weinreben, S., and Fehres, F.: The sound speed anomaly of Baltic seawater, Ocean Sci., 12, 275-283, https://doi.org/10.5194/os-12-275-2016, 2016.

Wagner, W. and Kretzschmar, H.-J.: International Steam Tables, Springer-Verlag Berlin, Heidelberg, 2008.

Wagner, W. and Pruß, A.: The IAPWS Formulation 1995 for the Thermodynamic Properties of Ordinary Water Substance for General and Scientific Use, J. Phys. Chem. Ref. Data, 31, $387-$ 535, https://doi.org/10.1063/1.1461829, 2002.

Wagner, W., Riethmann, T., Feistel, R., and Harvey, A. H.: New Equations for the Sublimation Pressure and Melting Pressure of $\mathrm{H}_{2} \mathrm{O}$ Ice Ih, J. Phys. Chem. Ref. Data, 40, 043103, https://doi.org/10.1063/1.3657937, 2011.

Wallace, W. J.: The Development of the Chlorinity/Salinity Concept in Oceanography, Elsevier, Amsterdam, London, New York, 1974. 
Waters, J. F. and Millero, F. J.: The free proton concentration scale for seawater $\mathrm{pH}$, Mar. Chem., 149, 8-22, https://doi.org/10.1016/j.marchem.2012.11.003, 2013.

Weir, R. D. and Goldberg, R. N.: On the conversion of thermodynamic properties to the basis of the International Temperature Scale of 1990, J. Chem. Thermodyn., 28, 261-276, https://doi.org/10.1006/jcht.1996.0026, 1996.

Wells, N. C.: The Atmosphere and Ocean, Wiley-Blackwell, Oxford, 2012.

Wiechert, H., Krienke, H., Feistel, R., and Ebeling, W.: Interionische Wechselwirkung und Thermodynamik starker Elektrolyte, Z. Phys. Chem.-Leipzig, 259, 1057-1076, 1978.

Wirth, H. E.: The Problem of the Density of Seawater, J. Mar. Res., 3, 230-247, 1940.

WMO: Guide to Meteorological Instruments and Methods of Observation, 7th edn., World Meteorological Organization, Geneva, Switzerland, available at: https://library.wmo.int/pmb_ ged/wmo_8_en-2012.pdf (last access: 11 June 2018), 2008.

WMO: Report on the WMO-BIPM workshop on Measurement Challenges for Global Observation Systems for Climate Change Monitoring: Traceability, Stability and Uncertainty, WMO Headquarters, Geneva, Switzerland, 30 March-1 April 2010.

Wolf, H.: Determination of water density: limitations at the uncertainty level of $1 \times 10^{-6}$, Accredit. Qual. Assur., 13, 587-591, https://doi.org/10.1007/s00769-008-0442-2, 2008.
Woosley, R. J., Huang, F., and Millero, F. J.: Estimating absolute salinity (SA) in the world's oceans using density and composition, Deep-Sea Res. Pt.I, 93, 14-20, 2014.

Wright, D. G., Feistel, R., Reissmann, J. H., Miyagawa, K., Jackett, D. R., Wagner, W., Overhoff, U., Guder, C., Feistel, A., and Marion, G. M.: Numerical implementation and oceanographic application of the thermodynamic potentials of liquid water, water vapour, ice, seawater and humid air - Part 2: The library routines, Ocean Sci., 6, 695-718, https://doi.org/10.5194/os-6-695-2010, 2010a.

Wright, D. G., Pawlowicz, R., McDougall, T. J., and Feistel, R.: Progress Report for the SCOR/IAPSO Working Group 127 on "Thermodynamics and Equation of State of Seawater", Canadian Ocean Science Newsletter 49, 30 March 2010, Canadian National Committee for SCOR, available at: http://cmosarchives. ca/scor/NL30Mar2010.pdf (last access: 11 June 2018), $2010 \mathrm{~b}$.

Wright, D. G., Pawlowicz, R., McDougall, T. J., Feistel, R., and Marion, G. M.: Absolute Salinity,"'Density Salinity" and the Reference-Composition Salinity Scale: present and future use in the seawater standard TEOS-10, Ocean Sci., 7, 1-26, https://doi.org/10.5194/os-7-1-2011, 2011. 